\title{
Análise de dados de Sensoriamento Remoto nas estimativas de variabilidade espacial e temporal de superfícies de inundação na planície fluvial do rio Javaés, TO
}

\author{
Analysis of Remote Sensing data in the estimation of spatial and temporal variability of flood \\ surfaces in the Javaés river plain, TO
}

\author{
Daniel Araujo Ramos dos Santos \\ Mestre em Geografia/Instituto de Estudos \\ Socioambientais (IESA/UFG), Brasil \\ daniel.a.sants@hotmail.com \\ Luis Felipe Soares Cherem \\ Doutor em Geografia/ Instituto de Estudos \\ Socioambientais (IESA/UFG), Brasil \\ luis.cherem@gmail.com
}

\section{Resumo}

A presente pesquisa analisou a variabilidade da inundação na zona deposicional do rio Javaés, relacionando os resultados com a dinâmica de precipitação e vazão entre 1984 e 2020. Dados de Sensoriamento Remoto foram processados na plataforma Google Earth Engine, com a criação de mosaicos mensais e anuais de imagens da série LANDSAT, e dados do projeto TerraClimate. Dados de vazão média mensal de estações na região da bacia foram coletados no sistema Hidroweb. Assinaturas espectrais de pontos amostrais de inundação foram extraídas dos mosaicos por meio software Qgis. A análise de estatística descritiva das amostras com valores de reflectância da superfície possibilitou a identificação de um limiar para o fatiamento da Banda do SWIR1, gerando classificações temporais de superfície inundada. Os dados estimados e organizados também foram avaliados por testes de tendência sazonal de Mann Kendall. Os dados derivados do fatiamento da banda SWIR1 foram comparados com índices espectrais de identificação de água NDWI e MNDWI. Os resultados revelam que os índices espectrais apresentam valores inferiores de área mapeada quando comparados com os resultados do fatiamento da banda SWIR1, com concentração de área em rios e lagoas. Os dados revelam ainda que a sazonalidade climática estabelece ciclos de inundação monomodais, com maior recorrência em planos abaciados, atingindo um terço da área de estudo, com a redução de 3,3\% durante secas anuais. O teste de tendência Mann-Kendall indica forte regressão na ocorrência da inundação nos últimos 35 anos. Testes sazonais de Mann-kendall também indicam significativas regressões na vazão e precipitação no rio Javaés, com concentração nos meses de seca e no início das chuvas. Dados topográficos revelam que paleoformas no interior da ilha do Bananal controlam a conectividade entre áreas inundadas.

Palavras-chave: Áreas úmidas, Sensoriamento Remoto, Ilha do Bananal, Conectividade.

\begin{abstract}
This research analysed the variability of flooding in the depositional zone of the Javaés River, relating the results to the dynamics of precipitation and flow between 1984 and 2020. Remote Sensing data were processed in the Google Earth Engine platform, creating monthly and annual mosaics of images from the LANDSAT series and data from the TerraClimate project. Monthly average flow data from stations in the basin region were collected in the Hidroweb system. Spectral signatures of flood sample points were extracted from the mosaics through Qgis software. Descriptive statistics analysis of the samples with surface reflectance values enabled the identification of a threshold for SWIR1
\end{abstract}


band slicing, generating temporal flooded surface classifications. Mann Kendall seasonal trend tests also evaluated the estimated and organised data. The data derived from SWIR1 band slicing were compared with NDWI and MNDWI water identification spectral index. The results reveal that the spectral index shows lower values of the mapped area when compared to the SWIR1 band slicing results, with area concentration in rivers and lakes. Furthermore, the results reveal that climatic seasonality establishes monomodal flood cycles, with more recurrence in flooding basins, reaching a third of the study area, reducing 3.3\% during annual droughts. The Mann-Kendall trend test indicates a robust regression in the occurrence of flooding over the last 35 years. Seasonal Mann-Kendall tests indicate significant regressions in inflow and rainfall in the Javaés River, with a concentration in the dry months and at the beginning of the rains. Topographic data reveal that paleoforms in the interior of Bananal Island control the connectivity between flooded areas.

Keywords: Wetlands, Remote Sensing, Bananal Island, connectivity, time series

\section{INTRODUÇÃO}

Registros arqueológicos de diferentes períodos históricos evidenciam o papel crucial dos ambientes naturalmente inundáveis no desenvolvimento de diversas sociedades no mundo antigo (BARBIER et al., 1997; TURNER et al., 2000; BURN, 2018; MACKLIN; LEWIN, 2019). O ciclo natural de inundação é coordenado pela relação de sistemas geomorfológicos (rios e planícies de inundação) com as fases de precipitação, inundação e vazante, que viabilizam a manutenção pedológica e ecológica de diversas áreas úmidas na superfície terrestre (JUNK et al., 1989). Essa dinâmica permitiu a diversos povos como os egípcios, persas/babilônicos, hindus e chineses desenvolverem sistemas econômicos baseados em agricultura sazonal em grandes escalas, o que financiou a expansão destes grupos sobre grandes territórios (MALTBY, 2009; ZHUANG; KIDDER, 2014; SHAO et al., 2021). Segundo Brooks (2006) e Bernhardt et al. (2012), evidências palinológicas e estratigráficas no delta do rio Nilo revelam que este ambiente foi impactado por vários episódios de secas, com variações na frequência de precipitação nas zonas de cabeceiras durante o Holoceno médio e superior, eventos que correlacionaram com secas documentadas $(5.000,4.200$ e 3.000 A.P.).

$\mathrm{Na}$ era pós-moderna, as áreas sujeitas a inundação natural ainda desempenham papel de destaque nas cadeias produtivas humanas, com a otimização do uso agrícola e a captação de recursos hídricos (MITSCH; GOSSELINK, 2000; JUNK, 2013; JUNK et al., 2014, KANDUS et al., 2018). Neste contexto, o mapeamento de áreas úmidas, especificamente aqueles voltados para identificação dos status dinâmicos da água em superfície, podem ser importantes ferramentas para a mensuração das potencialidades e fragilidades destes ambientes, como o auxílio em tomadas de decisões políticas/administrativas voltadas a preservação e uso racional (HU et al., 2017). Alguns autores apontam que mapeamentos globais sobre as dimensões dos ambientes de inundação realizados até o início do século 21 apresentam diversas discrepâncias, devido principalmente a incompatibilidades de escalas regionais e uma falta de padronização metodológica, além de uma implícita subestimação 
do papel antrópico (FINLAYSON et al., 1999; REBELO et al., 2009; GUO et al., 2017). Tiner (2016) estimou que as áreas úmidas apresentam tendência de redução, ocupando entre 3 e $8 \%$ da superfície terrestre, com maior ocorrência em zonas boreais e árticas. O mapeamento global de águas abertas apresentado por Pekel et al. (2016), cobrindo o período entre 1985 e 2015, indica redução de aproximadamente $90.000 \mathrm{~km}^{2}$ de áreas úmidas, com maior impacto em regiões com uso intensivo do solo. Davidson et al. (2018) por meio do uso de dados de sensoriamento remoto revisaram e estimaram diversos inventários, e indicaram que estas áreas úmidas ocupam aproximadamente 12 milhões de $\mathrm{km}^{2}$.

No médio curso do rio Araguaia, a planície do Bananal se destaca como um importante compartimento influenciado pela sazonalidade climática, que condiciona ampla área úmida durante o período de chuvas, em uma região de transição entre o domínio do Cerrado e Floresta Amazônica (JUNK, 2013; IRON et al., 2016; MENDES, 2019). Essa área é definida como um compartimento regional da Bacia Sedimentar do Bananal, um complexo mosaico de unidades morfossedimentares que cobrem mais de 100 mil quilômetros quadrados, figurando entre as quatro maiores áreas inundadas na América do Sul (HAMILTON et al., 2002; VALENTE et al., 2013). Neste contexto, o histórico de análises geomorfológicas na bacia do rio Araguaia revela tendências de mudanças expressivas na morfologia da planície aluvial nas últimas décadas, em paralelo aos avanços da fronteira agrícola (MORAIS et al., 2008; BAYER; ZANCONPÉ, 2014; BAYER et al., 2020). De tal forma, observa-se que são poucos os trabalhos dedicados a avaliar a dinâmica de inundação na planície (várzeas). Destaca-se a inciativa de Hamilton et al. (2002) que mapearam em escala continental as maiores áreas úmidas na América do Sul, e IRON et al. (2016), que analisaram a abrangência dos pulsos de inundação e conectividade no alto é médio Araguaia.

A zona de deposição na bacia do rio Javaés compõe uma expressiva área da Planície do Bananal, e permite uma avaliação mais detalhada sobre como as forças motrizes e de emulação se integram e condicionam a paisagem em curto termo. No contexto climático, a área tem apresentado prolongamento do período de estiagem, resultando em secas hidrológicas mais severas que têm afetado os rios da região durante a última década (FLEISCHMANN, 2016; ESPINOZA et al., 2019). Neste contexto, percebeu-se a necessidade de compreender se a dinâmica de inundação apresenta tendências de ajuste por parte de fatores controladores (climáticos, geológicos e geomorfológicos) em curto termo.

Disto exposto, a presente pesquisa buscou analisar a variabilidade espacial e temporal do processo de inundação na zona deposicional da bacia do rio Javaés, considerando a dinâmica das variáveis climáticas e geomorfológicas. Desta forma, foram realizadas análises conjuntas de dados de Sensoriamento Remoto gerados entre 1984 a 2020, séries hidrológicas de vazão e dados de 
precipitação de mesmo período. Modelos de hidroperíodo são apresentados, com a caracterização da ocorrência da inundação, assim como análises de tendências e correlação entre dados destacados.

\section{MATERIAIS E MÉTODOS}

\section{1. Área de estudo: Aspectos geológicos e geomorfológicos}

O trado deposicional do rio Javaés compõe o médio curso da bacia do rio Araguaia, compreendendo uma porção significativa da ilha do Bananal (Figura 1).

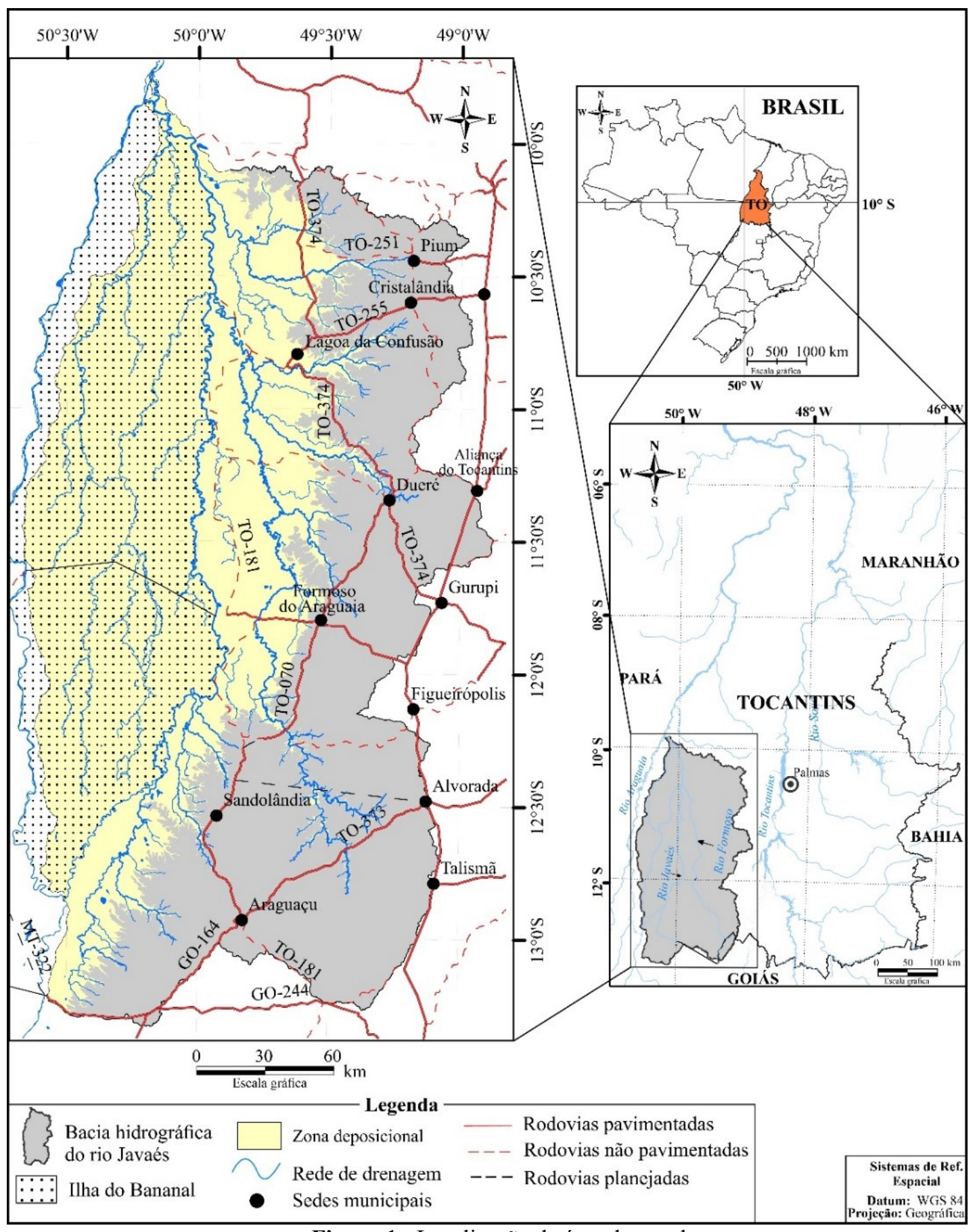

Figura 1 - Localização da área de estudo.

Fonte: os autores. 
Em termos geológicos, situa-se na porção leste da Bacia Sedimentar do Bananal, um amplo compartimento intracratônico com aproximadamente $106.000 \mathrm{~km}^{2}$ (SILVA et al., 2003). Registros sedimentares indicam que o ambiente apresenta desenvolvimento por fases de deposição fluvial e lacustre, marcado por oscilações climáticas pleistocênicas (VALENTE; LATRUBESSE, 2012).

Mapeamentos regionais indicam que esse baixo estrutural é controlado por um sistema de falhas e fraturas associadas ao Lineamento Transbrasiliano (LTB), que é preferencialmente orientado no sentido SW-NE e apresenta diferentes fases de reativação (ASSINE; SOARES, 2004; SANTOS et al., 2013); falhas do Lineamento Tocantins-Araguaia, reconhecidos com orientação preferencial junto a Faixa Araguaia no sentido S-N, com estruturas recobertas por material inconsolidado no contato com o Cráton Amazônico (MAMEDE et al., 1981; IBGE, 2007).

As unidades cenozoicas são organizadas regionalmente por Stropper et al. (2014) em três conjuntos: 1) depósitos aluvionares com idade holocênica, originados da migração lateral dos rios, formando planícies aluviais ativas com espirais de meandros, 2) Formação Araguaia com fáceis arenosa, laterítica e aluvial em idade pleistocênica, e fácies de terraços aluvionares compostos por material síltico-argiloso, arenoso, semiconsolidado e parcialmente laterizado (120.000 a 34.000 A. P.); 3) Coberturas detrito-lateríticas com horizonte concrecionário e ferruginoso inconsolidados, distribuídas como núcleos superficiais contínuos de material areno-argiloso, marcando uma transição do neógeno para o pleistoceno. Conforme o mapeamento geológico do IBGE (2007), 78\% da área está associada a unidade da Formação Araguaia (Q1Q2b).

\subsection{Fonte dos materiais}

Foram selecionados dados vetoriais de Geologia, Geomorfologia e Pedologia disponibilizados pelo Instituto Brasileiro de Geografia e Estatística, na escala de 1:250.000. Imagens orbitais do satélite LANDSAT 4 e 5 (L4 e L5), sensor TM (Tematic Mapper); LANDSAT 7 (L7), sensor ETM+ (Enhanced Thematic Mapper Plus); também LANDSAT 8 (L8), sensor OLI (Operational Terra Imager) (Figura 2). As imagens foram selecionadas a partir de scripts elaborados na plataforma Google Earth Engine (GEE), por meio da filtragem de metadados da coleção Surface reflectance (SR), dados já pré-processados e disponibilizados pela United States Geological Survey (USGS), com ortorretificação e correção atmosférica (SCHMIDT et al., 2013). Também foi criado um mosaico de imagens do satélite Sentinel 2B (2017-2020), sensor MSI (multi-spectral instrument), especificamente as bandas Blue, Green, Red e NIR, da coleção da European Space Agency (ESA).

Foi utilizado o Modelo Digital de Superfície (MDS) AW3D do projeto ALOS (Advanced Land Observing Satellite) de 2018, gerado pelo processamento de dados do sensor Pancromático PRISM, elaborado pela JAXA (Japan Aerospace eXploration Agency), com resolução espacial de 30 
m. Ainda no GEE foram coletados dados do projeto TerraClimate de precipitação, evapotranspiração e déficit hídrico (def), conforme as definições de Abatzoglou et al. (2018). Dados de vazão média mensal organizados e distribuídos pela Agência Nacional das Águas (ANA) foram coletados de duas estações no rio Javaés: Barreira do Pequi e Barreira da Cruz, e para fins de ajustes nas séries históricas, dados de três estações no rio Araguaia: Aruanã, Luís Alves e São Felix.

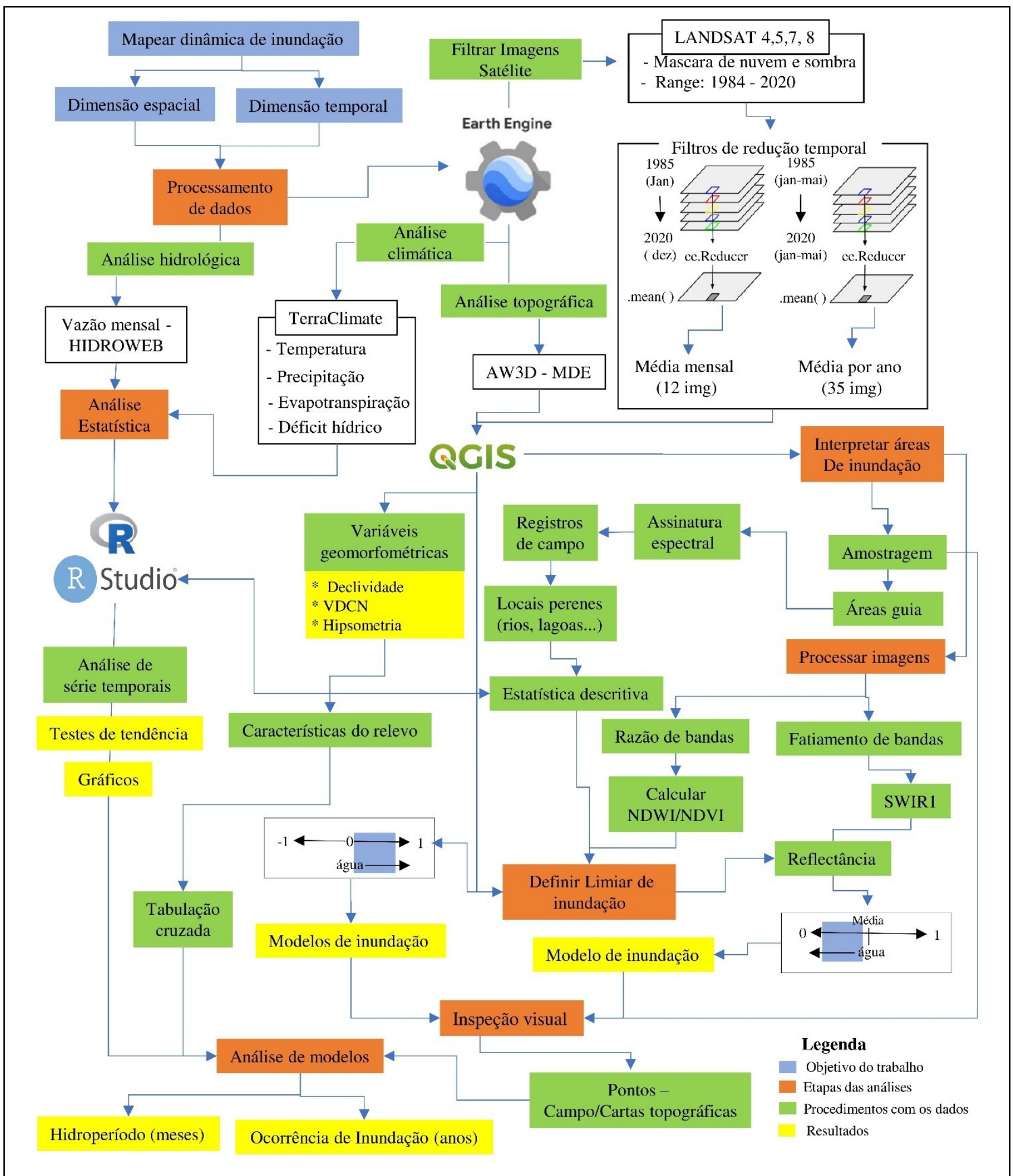

Figura 2- Fluxograma dos procedimentos metodológicos adotados na pesquisa.

Fonte: os autores. 


\subsection{Processamento e Análise dos dados}

No Qgis 3.16 foi feita a delimitação da bacia hidrográfica e da rede de drenagem do rio Javaés por meio da interpretação visual das imagens do Sentinel 2 e do MDE AW3D, conforme Santos e Morais (2017). A zona deposicional foi delineada de forma vetorial a partir da análise conjunta de unidades deposicionais e modelados de acumulação definidos pelo mapeamento do IBGE (2007), e variáveis topográficas derivadas do MDE. Por meio da ferramenta Vertical Distance to Channel Network (VDCN), foi definido um modelo classificado em quebras naturais da altura do relevo em relação a drenagem mais próxima. Assim, estas informações combinadas com rotinas de análises de perfis longitudinais e varredura possibilitaram a identificação de pontos de quebra no relevo (SILVA; DA SILVA, 2018).

No GEE foram criados dois conjuntos de imagens de redução derivadas das coleções do LANDSAT, através de processos de filtragem espacial, espectral e temporal (Figura 3), considerando limite da zona deposicional. Para a área de estudo, foram encontradas 31 cenas do L4, 4.174 do L5, 4.803 do L7 e 2.155 do L8. O percentual máximo de cobertura de nuvens e sombras estabelecido por cenas foi de $60 \%$. Sobre estas imagens foi aplicada uma função de máscara de pixel baseada no algoritmo C Function of Mask (CFMask), que qualifica os pixels de cada cena e possibilita mascarar nuvens e sombras nas imagens (SCHMIDT et al., 2013). Estes processos resultaram em um conjunto reduzido e qualificado de 9.178 cenas.

Entre os filtros de redução espectral testados, optou-se pela relação de média entre as imagens encontradas para o período estabelecido. Desta forma, criou-se um primeiro grupo corresponde a 12 imagens com valores de reflectância média para cada mês, entre 1985 e 2020; o segundo grupo corresponde a 35 imagens com valores médios representativos de um determinado ano, considerando apenas os meses de intensificação da precipitação e consequentemente maior probabilidade de cheias/inundação na área de estudo. Aplicou-se os índices baseados na razão de bandas espectrais mais comuns para a identificação de água em superfície (FEYISA et al., 2014; ACHARYA et al., 2018; FISHER, et al., 2016), como o Normalized Difference Water Index (NDWI) proposto por Mcfeeters (1996, 2013), e o Modified Normalized Difference Water Index (MNDWI), modelo aperfeiçoado por XU (2006).

Conforme Meneses e Almeida (2012) e Barbosa (2019), a água apresenta resposta de refletância da superfície muito baixa nas faixas do visível e infravermelho quando comparada com outros alvos como solo e vegetação. Jensen e Epiphanio (2009) indicam em ensaios que a diferenciação de corpos aquáticos em relação a outros alvos é melhor observada nas faixas do infravermelho próximo e médio (entre 740 e $2500 \mathrm{~nm}$ ), já que neste domínio espectral a água apresenta uma relação inversa com coeficientes de espalhamentos baixos e de absorção altos, 
comportando como um corpo negro. Zani e Rossetti (2012) também observam que água liquida apresenta valores de reflectância baixos a medida que ocorre o aumento dos comprimentos de onda. Os autores sugerem a estratégia de identificação de um limiar adequado para o fatiamento de banda SWIR1 do LANDSAT (Figura 3), se destacando entre outras técnicas como um método de alta acurácia e de rápido processamento.

Para a aplicação do fatiamento de imagens SWIR1, foi elaborada uma chave de interpretação baseada na observação das condições hidroclimáticas em locais selecionados, e amostragem de zonas de controle para coleta de assinatura espectral de pixels de água, coletadas no Qgis sobre os mosaicos de imagens preparados. Ao considerar os pressupostos apresentados por Menezes e Almeida (2012), a escala cartográfica identificada nos dados gerados derivados das imagens LANDSAT (30m/pixel) foi de 1:100.000. Desta forma, a posição dos pontos foi validada pelo reconhecimento de massas de águas e ambientes úmidos presentes no mosaico de cartas topográficas de 1:100.00 do DSG, com auxilio visual de imagens de alta resolução presentes no Google Maps, disponíveis virtualmente no Qgis. Zonas circulares com raio de $150 \mathrm{~m}$ foram distribuídas sobre rios, lagoas e suas bordas (auréola de colmatagem), várzeas e meandros abandonados. Os dados amostrais foram trabalhados no software de estatística R 4.2 (R CORE TEAM, 2020). Com as informações organizadas por mês, foram elaborados gráficos de violino e bloxplots com a finalidade identificar valores anômalos e tendências de distribuição (Figura 3).

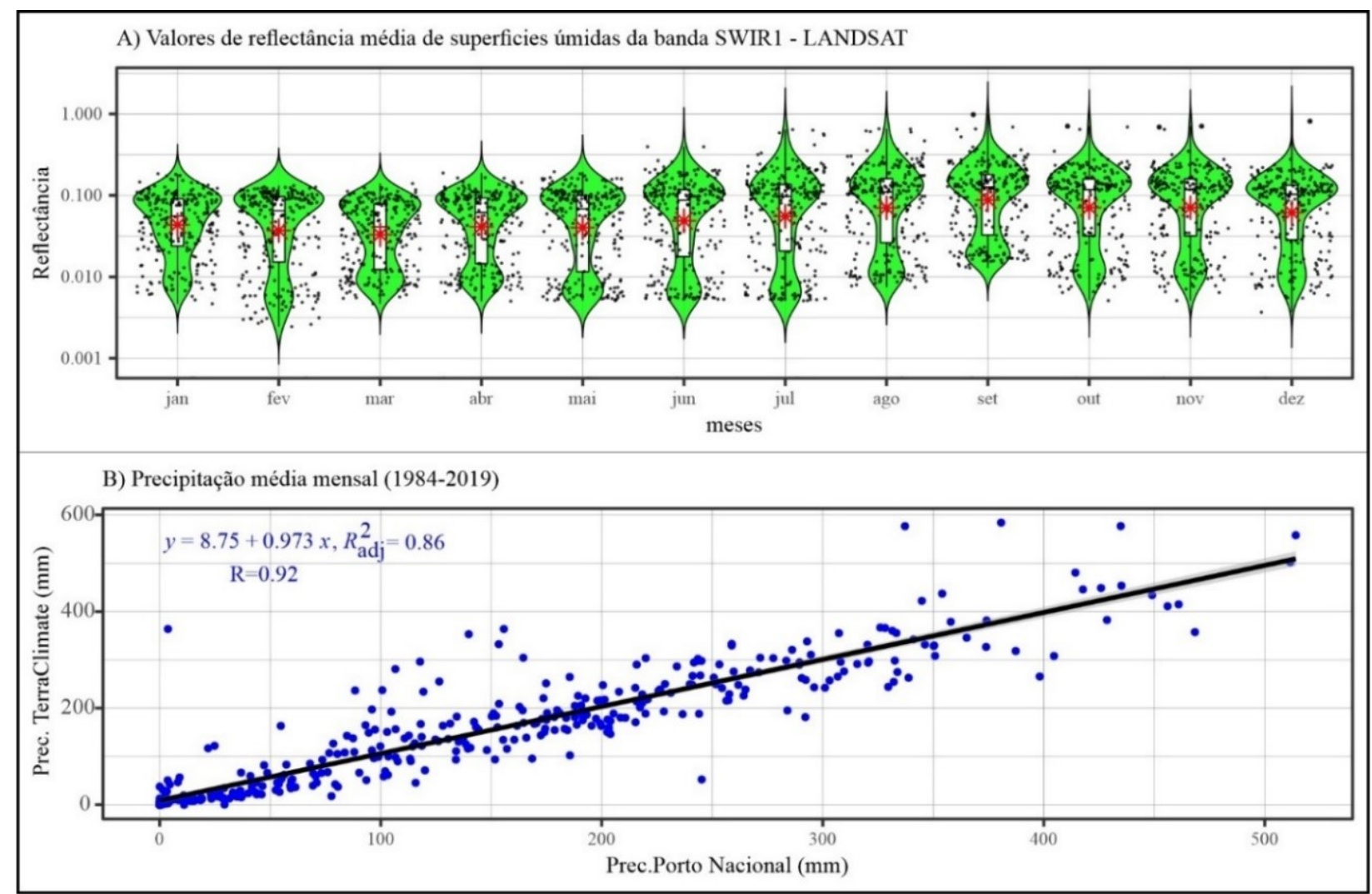

Figura 3 - Representações gráfica dos valores amostrais de refletância da água por mês (A). Gráfico de dispersão da relação de dados de chuva entre estação convencional e o TerraClimate (B). Fonte: os autores. 
Os valores de reflectância da superfície foram normalizados entre 0 e 1 . Os pontos distribuídos nos gráficos na figura 3 ao longo de cada conjunto mensal indicam as posições das amostras no decorrer da série anual; os traços vermelhos indicam a posição da mediana e o asteriscos em vermelho os valores de média por mês. No primeiro quartil entre meses representa a possível resposta espectral de pixels puros em ambientes somente com água (JENSEN, EPIPHANIO, 2009). Os valores próximos a 0,12 são identificados como correlacionáveis com ambientes com vegetação aquática ou de vegetação arbustiva e campestre, como o Campo Sujo Úmido e o Parque Cerrado, ambos com murundus (RIBEIRO; WALTER, 1998; BARBOSA, 2019).

$\mathrm{Na}$ figura 3A, os dados plotados e ajustados a base de $\log 10$ indicam uma densificação das amostras concentradas entre o terceiro e quarto quartil, com distribuição assimétrica na maior parte dos meses de forma unimodal, e discreta distribuição bimodal nos meses de transição da estação chuvosa para seca (maio) e de seca para chuvosa (setembro). Em comparação a distribuição anual das chuvas, observou-se que os valores de reflectância são correlacionáveis com as taxas de precipitação e de vazão dos rios, conforme Zani e Rossetti (2012), com redução dos valores de refletância em meses chuvosos (entre dezembro e abril) e consequentemente elevação nos valores de reflectância nos meses de estiagem (entre junho novembro). Desta forma, ao considerar o comportamento da amostragem em diferentes ambientes, estabeleceu-se como limiar de fatiamento da banda SWIR1 para a separação binária de ambiente com saturação hídrica, sendo todos os valores com referência de ND menor que 0,10 .

Os dados climáticos do TerraClimate foram pré-organizados no GEE como séries temporais de médias e acumulados mensais entre 1984 e 2020 da precipitação, evapotranspiração e déficit hídrico. Por se tratar de dados matriciais, foi aplicado funções de redução por região (área de estudo) para valores médios. Posteriormente os dados foram analisados no software $\mathrm{R}$, com a aplicação de testes de regressão linear simples para a verificação de precisão das informações em relação a dados convencionais. Foi utilizado dados da estação Porto Nacional - TO, única na região com série temporal completa (1984-2019) (Figura 3B). A Correlação entre as variáveis apresentou valores pvalor $<0,01$, com um forte grau de dependência positiva, com valor de $\mathrm{R}$ de 0,92 , e de $\mathrm{R}^{2}$ ajustado ( $\left.\mathrm{R}^{2} \mathrm{adj}\right)$ de 0,86 .

O teste não paramétrico de Mann-Kendall foi utilizado para se verificar a presença ou ausência de tendência nos dados ao longo de séries temporais (YAN et al., 2020). Para os dados de inundação, utilizou-se o a função 'mk.test' do pacote TREND no R, onde se verifica se os dados da variável ambiental(y) apresentam mudanças em função da variável de tempo (x). Assim, duas hipóteses são testadas: H0 - hipótese nula: Não há tendência nos dados; H1 - hipótese alternativa: Uma tendência está presente nos dados, que pode ser de elevação ou redução (HELSEL; FRANS, 2006). Desta forma, o teste estabelece a rejeição de H0 conforme a significância do valor de p adotado (KAHYA; 
KALAYCI, 2004). Para os dados com sazonalidade (variáveis climáticas e vazão média mensal), aplicou-se o teste de Mann-Kendall modificado - Seasonal Kendall trend Test, com os mesmos pressupostos de interpretação que sua versão simples, porém com avaliação adequada para avaliação de dados sazonais. O valor de estatística $\mathrm{S}$ indica a direção da série, podendo ser negativa (baixa) ou positiva (alta), e o índice tau é a normalização deste parâmetro com valores entre -1 a 1 .

Os dados de vazão média mensal das estações fluviométricas Barreira do Pequi e Barreira da Cruz, apresentaram respectivamente 30 e 20 meses vazios entre 1984 e 2020. Desta forma, optou-se em preencher estas lacunas por meio da função "FillGap" do pacote "Hyfo" no software R (XU, 2020), por meio de correlações entre estações na região. A ferramenta é baseada na estratégia de Hirsch e Slack (1984), que: calcula o coeficiente de correlação, criando duas matrizes: a primeira indica a melhor ordem de ajuste entre as colunas; a segunda é uma matriz de correlação entre estações (método Pearson). Posteriormente, aplica-se regressão linear simples por pares de colunas mais próximas, que junto a uma função de predição incrementada ao modelo e estima os valores ausentes (equação $\mathrm{y}=\mathrm{a} * \mathrm{x}+$ ).

\section{RESULTADOS}

\subsection{Condições hidroclimáticas na porção deposicional da bacia do rio Javaés}

A bacia do rio Javaés possui uma área de $53.037 \mathrm{~km}^{2}$ e uma rede de drenagem de $8^{\circ}$ ordem (conforme modelo de Strahler), com um total de 16.112 canais. Já a zona deposicional corresponde a uma área com $29.775 \mathrm{~km}^{2}$, sendo $56 \%$ em relação a toda a bacia, com uma rede de drenagem com 3.175 canais com $14.517 \mathrm{~km}$ de extensão. O índice Densidade de drenagem na zona deposicional é de $0,488\left(\mathrm{~km} / \mathrm{km}^{2}\right)$ e Densidade hidrográfica de 0,10 Canais $/ \mathrm{km}^{2}$.

A figura 4 sistematiza informações de área inundada em média mensal (1985-2020) mapeadas na zona deposicional, conforme os métodos SWIR1, NDWI e MNDWI, além dados climáticos e de descarga. O eixo secundário no gráfico da figura 4A corresponde aos valores de precipitação, evapotranspiração e déficit hídrico em escala de mm em médias mensais. A área de estudo possui um clima úmido com moderada deficiência hídrica, com duas estações bem definidas: inverno com estiagem de 4 a 5 meses sem precipitação, ocasionando as secas dos rios, queda na evapotranspiração em consonância com stress da vegetação de Cerrado, déficit hídrico com pico em agosto até meados de setembro; o verão é uma fase úmida com chuvas no início em setembro, intensificadas até abril do ano seguinte. A precipitação média mensal mais acentuadas são recorrentes entre dezembro e janeiro; (SANTOS; MORAIS, 2017).

O hidrograma de vazão média por mês (Figura 4B) indica um padrão de distribuição monomodal da descarga, com volume mais acentuados na Barreira da Cruz (jusante), enquanto que 
a Barreira do Pequi (montante) possui amplitude de vazão relativamente menor. Nota-se que a seca hidrológica acompanha a baixa resposta de área de inundação, com vazões inferiores a $100 \mathrm{~m}^{3} / \mathrm{s}$ mensais, mesmo em meio ao restabelecimento da precipitação entre outubro e dezembro.

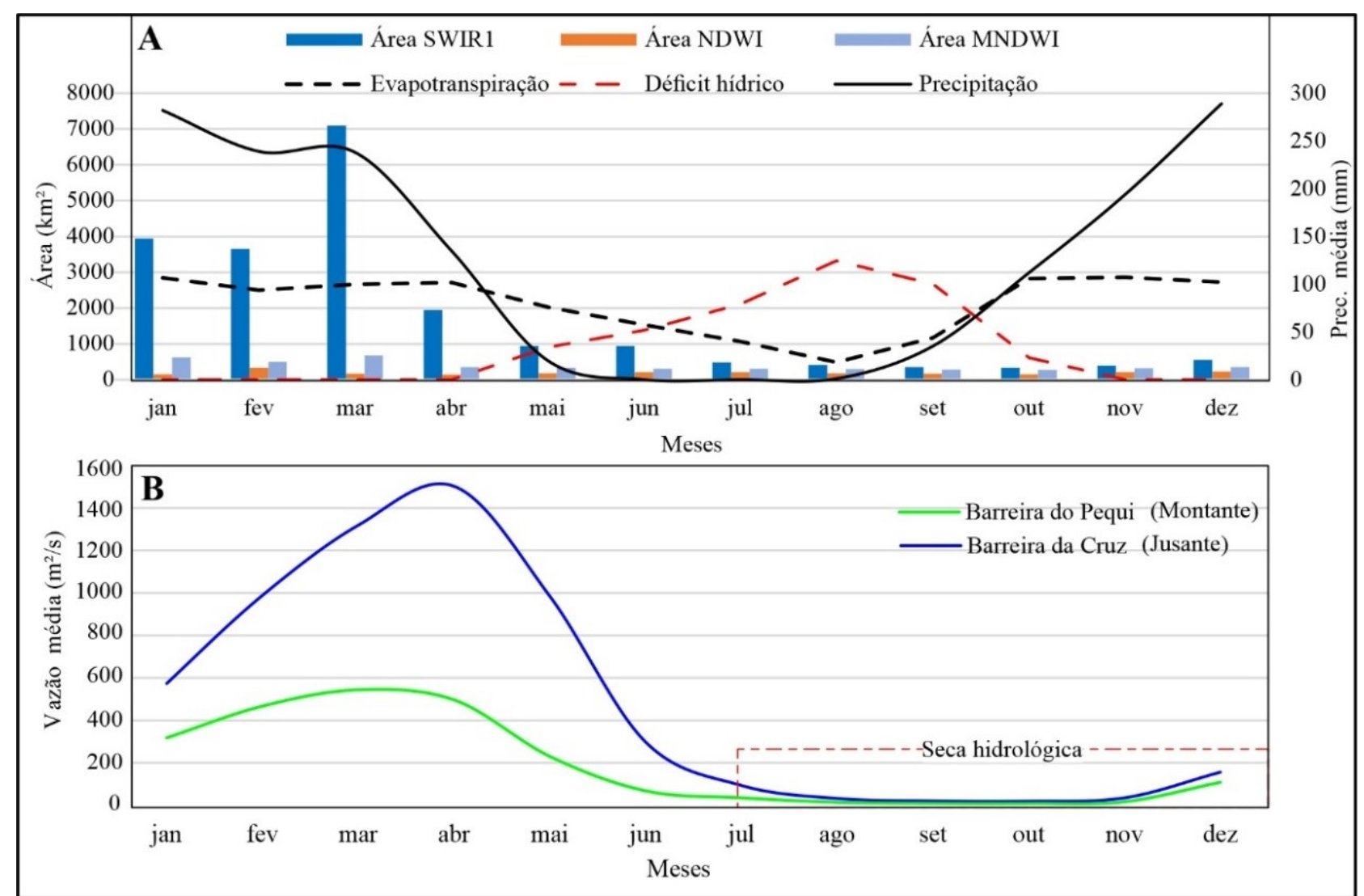

Figura 4 - A) Distribuição média mensal de área de inundação por métodos e dados climáticos; B) Vazão média mensal por estações no baixo curso do rio Javaés. Fonte: os autores.

Os dados da abordagem com SWIR1 apresentaram em média valores superiores em todos os meses para áreas com água quando comparado com os índices NDWI e MNDWI. O modelo derivado do SWIR1 apresentou distribuição mais heterogênea enquanto que os índices concentraram-se nas proximidades de rios e lagoas. O modelo de distribuição anual do SWIR1 é assimétrico com maiores extensões de área entre os meses de janeiro e abril, com pico de área máxima atingida pela cheia em março $\left(7.090 \mathrm{~km}^{2}\right)$. O decréscimo total nas taxas de precipitação ocorre entre janeiro e julho, refletindo também em uma redução gradativa de área inundada neste período. Assim a fase de vazante segue o período com rápido recuo de áreas inundadas em $73 \%$ entre março e abril, e 55\% entre abril e maio, seguido de acentuado recuo da descarga na Barreira da Cruz.

Conforme a figura 4A, a redução de área desacelera nos meses de junho e julho, sendo relacionável aos valores do déficit hídrico elevado, com ápice em agosto (125 mm), com relação inversa aos valores de evapotranspiração. Entre junho e outubro a estação de seca se estabelece na região, e o percentual de área com saturação hídrica é restringido as zonas fluviais e lacustres, com 
possível redução da conectividade lateral e longitudinal entre sistemas de canais, planos de inundação e planície aluvial (IRON et al., 2016). Entre agosto e setembro os níveis de água em superfície continuam a reduzir $(-15 \%)$, com continuidade da queda entre setembro e outubro $(-6 \%)$, porém à medida que a precipitação é restabelecida ocorre a redução do déficit hídrico e a rápida elevação e estabilização nos valores de evapotranspiração (em média 100 mm/mensais).

Os Modelos de hidroperíodo derivados do NDWI e MNDWI apresentam baixa amplitude de área e pouca variabilidade espacial no decorrer dos meses (Figuras 4 e 5). Os valores mais elevados ocorrem em fevereiro para NDWI $\left(333 \mathrm{~km}^{2}\right)$ e março para MNDWI $\left(497 \mathrm{~km}^{2}\right)$. Espacialmente as áreas úmidas definidas pelo MNDWI correspondem aos ambientes com perenidades em boa parte do ano, como lagoas, represamentos artificiais e trechos de rios, e algumas áreas de modelado fluviolacustres no interior da ilha (Figura 5B).

Modelos de frequência mensal e ocorrência anual foram mensurados conforme lógica boleana, pela soma de máscaras de água mensais, sendo atribuindo valor 1 para pixel mapeado com água, e valor 0 para sem água (Figuras 5). A escala indica a quantidade de meses que o local permanece com inundação. Conforme comparativo da figura 5, nota-se padrão anual de frequência do MNDWI, com concentração de água em zonas aluviais e lacustres. Os locais com 11 e 12 meses nessa classificação respondem a zonas perenes e representam $1,1 \%$ da área de estudo. Já o modelo de soma do SWIR1 (Figura 5A) indica que $70 \%$ da área não apresenta fase de inundação. A faixa sazonal é extensa no modelo, com frequência entre 1 até 5 meses. Nota-se que a resposta sazonal é melhor destacada no SWIR1. 13,2\% de área são inundadas durante um mês, e 7,7 \% em até dois meses, com distribuições próximas as zonas aluviais. Apenas $3,2 \%$ da área sustenta ambientes com água durante todo o período. 


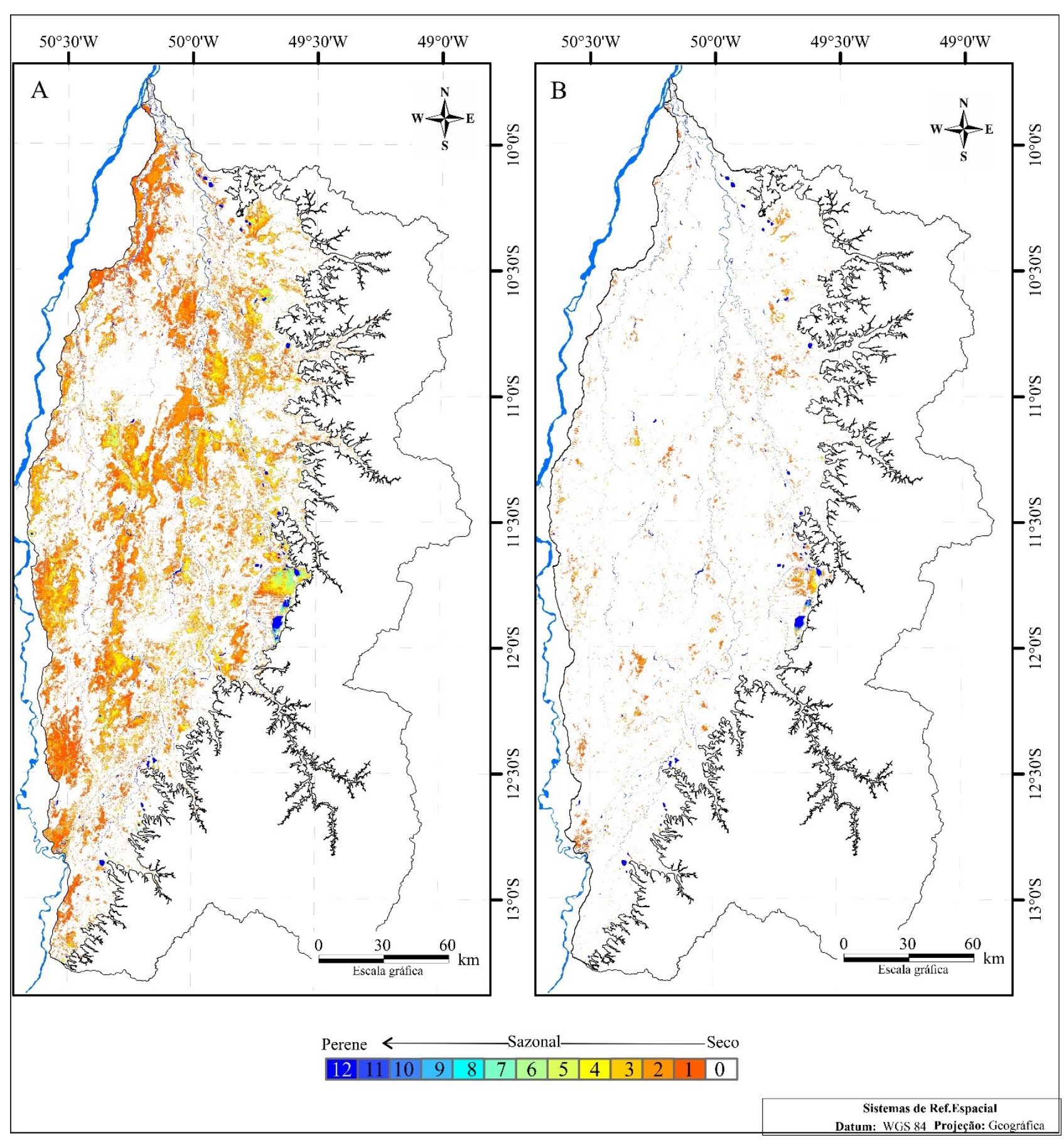

Figura 5 - Modelos de hidroperíodo derivados da interpretação e soma das bandas mensais. A) SWIR1; B) MNDWI. Fonte: os autores.

\subsection{Variabilidade temporal da inundação}

A partir da abordagem de fatiamento da banda do SWIR1, identificou-se que às áreas de inundação são influenciadas pela sazonalidade regional do clima e geradas com uma defasagem temporal reativa a acentuação das chuvas (Figura 4). De tal forma, assumindo os mesmos pressupostos de fatiamento do SWIR1, avaliou-se a dinâmica de inundação do baixo curso do rio Javaés entre 1985 e 2020. Essa abordagem considerou somente os meses de intensa pluviometria (entre janeiro e maio) (Figura 4A). O modelo gerado indica alta variabilidade de extensão das áreas 
saturadas entre os anos e décadas, com diferentes taxas de expansão e retração (Figura 6). O ano de maior expansão da inundação foi $1986\left(9.412 \mathrm{~km}^{2}\right)$, correspondendo a 32\% da área total, seguido de $1995\left(8.824 \mathrm{~km}^{2}\right)$ com 30\% de área e 1985 com $7.494 \mathrm{~km}^{2}$ (26\%). situação oposta foi identificada em 1998 com $788 \mathrm{~km}^{2}$ (2,6\%), 2016 com $895 \mathrm{~km}^{2}$ e 2008 com $1038 \mathrm{~km}^{2}$ (3,5\%). Entre os 35 anos avaliados, 22 anos apresentam área menor que $2.914 \mathrm{~km}^{2}(9,8 \%)$.

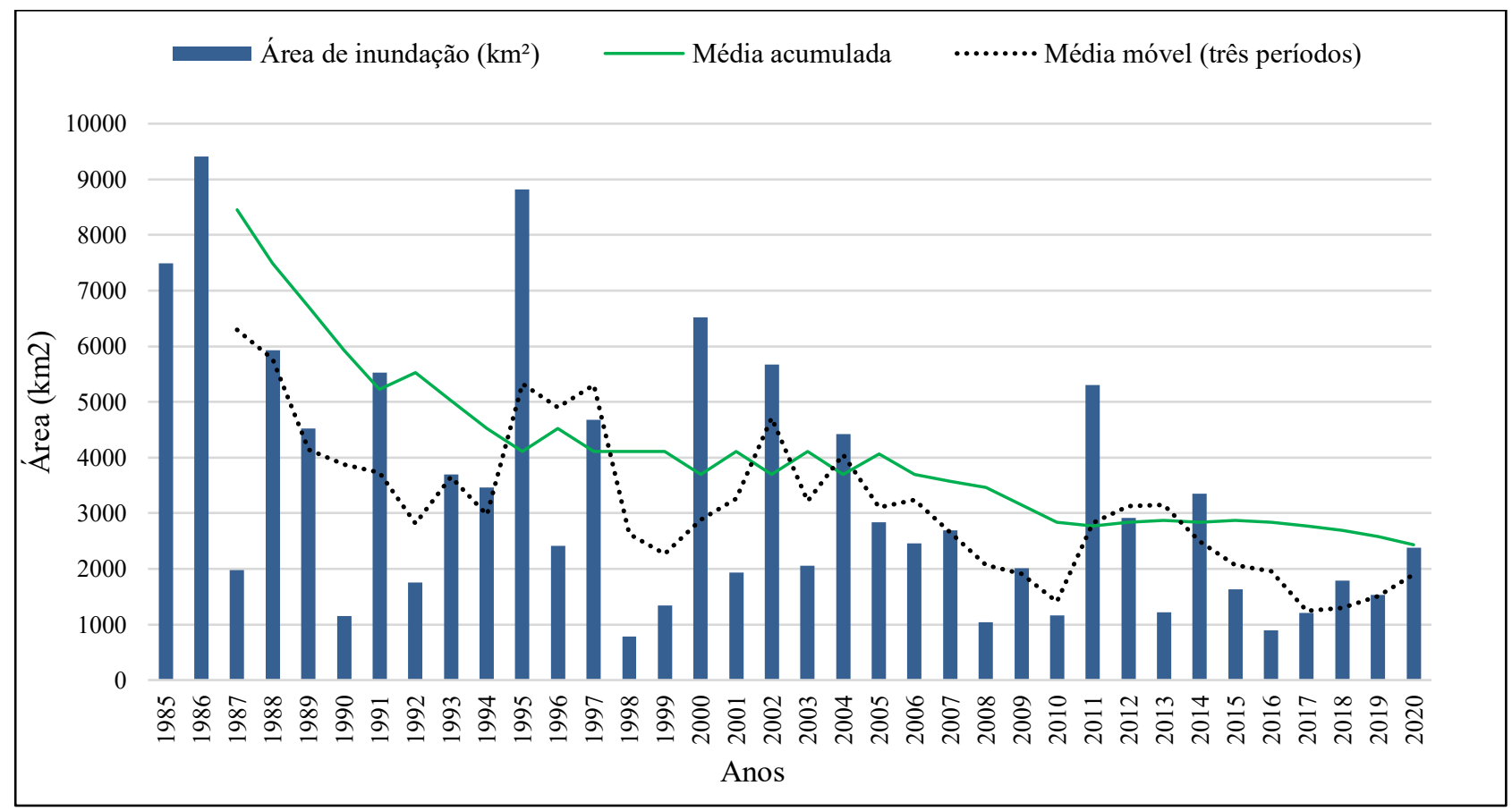

Figura 6 - Quantitativo de área máxima inundada na área de estudo entre 1985 a 2020.

Fonte: os autores.

A ferramenta de média móvel ajustada para três anos consecutivos foi utilizada para verificar tendências na série temporal de inundação anual, suavizando as flutuações entre anos (Figura 6). A análise da média móvel indica uma tendência geral de decréscimo na série histórica em degraus, com variação de ciclos marcados por alternâncias entre altas e baixas frequências de inundação. A média móvel acumulada também de três anos consecutivos reforça a interpretação de queda gradual nos valores máximos e de amplitude entre ciclos. Os anos de 1992 e 1994 marcam mudanças de tendência na primeira década (1985-1995), com valores que variavam em faixa de amplitude de $8.258 \mathrm{~km}^{2}$.

Um novo ciclo entre picos é observado entre 1995 e 2002, com valores confinados em amplitude de área $8.036 \mathrm{~km}^{2}$, indicando curto patamar entre 1995 e 1997, por súbita queda entre 1998 e 1999. Entre 2000 e 2004 ocorre uma elevação em média de área inundadas com pico em 2002, porém com forte redução de amplitude de inundação da curva de média acumulada até 2010. O último ciclo observado está entre 2011 e 2020, inicia-se com a quarta maior frequência de área inundada $8 \%$ $\left(5.300 \mathrm{~km}^{2}\right)$ em toda a série. Nessa sequência final, destacando entre 2013 e 2020, é registrada a menor amplitude de valores de área na série histórica. Nesse período a região se destacou em 
noticiários regionais e nacionais, devido os impactos do período de estiagem (MPF, 2013; SILAS, 2016; G1, 2017; JORNAL NACIONAL, 2019).

De forma similar aos modelos apresentados de hidroperíodo (Figura 5), os dados de inundação anuais foram somados e normalizados em porcentagem. Desta forma, quanto maior o percentual (\%/ano) mais regular e recorrente é o fenômeno no período avaliado (Figura 7). A interpretação do mapa na figura 7A, junto a curva de permanência (Figura 8) que faz uma relação exponencial entre a quantidade de área afetada e tempo, permite identificar alguns padrões. $12.326 \mathrm{~km}^{2}$ (42\%) da área não apresentou fases de inundação anual, $3.820 \mathrm{~km}^{2}(12 \%)$ apresentaram ocorrência de 2,3\% de tempo. $8.129 \mathrm{~km}^{2}(27 \%)$ com recorrência entre 6 e 20\% de tempo, $5.024 \mathrm{~km}^{2}$ (16\%) de área com ocorrência entre $23 \%$ e $89 \%$ de tempo. Os valores entre 90 e $100 \%$ correspondem a zonas com alta recorrência de inundação, incidentes em lagoas naturais e artificiais ou trechos de rios pouco afetados por eventos anuais de secas, sendo $1,6 \%$ da área de estudo.

O fatiamento por intervalos de quebras naturais dos valores da altura do relevo em relação a rede de drenagem (Figura $8 \mathrm{~B}$ ) indicou cinco extratos topográficos, sendo o primeiro de 0 a $1 \mathrm{~m}$ predominante em $65,8 \%$ da área $\left(19.000 \mathrm{~km}^{2}\right)$, com zonas localizadas no mesmo nível da rede de drenagem. Esta faixa mais próxima ao nível dos rios é observada entre os rios Javaés e Riozinho na porção norte da ilha do Bananal. Na porção central e sul da ilha, nota-se a segmentação dessas áreas abaciadas por uma rede de drenagem que está condicionada por paleofeições reativadas (IRON et al., 2016). Estas formas são definidas como um segundo grupo de relevância, com altura entre 1 a 4 m, e corresponde a $21 \%$ da área $\left(6.511 \mathrm{~km}^{2}\right)$. Os valores acima de $9 \mathrm{~m}$ foram subdividos em três grupos que somam $2 \%$ da área de estudo, e correspondem a morros e patamares elevados na planície de inundação, como feições residuais em quartzito e exocárste em calcários da Formação neoproterozóica Couto Magalhães (SANTOS; MORAIS, 2017).

A curva de distribuição ajustada por uma regressão exponencial (Figura 8) permite interpretar que em $20 \%$ do tempo ocorreu inundações com área total superior a $1000 \mathrm{~km}^{2}$, com concentração dos valores de área dos eventos entre 80 e $1000 \mathrm{~km}^{2}$. 


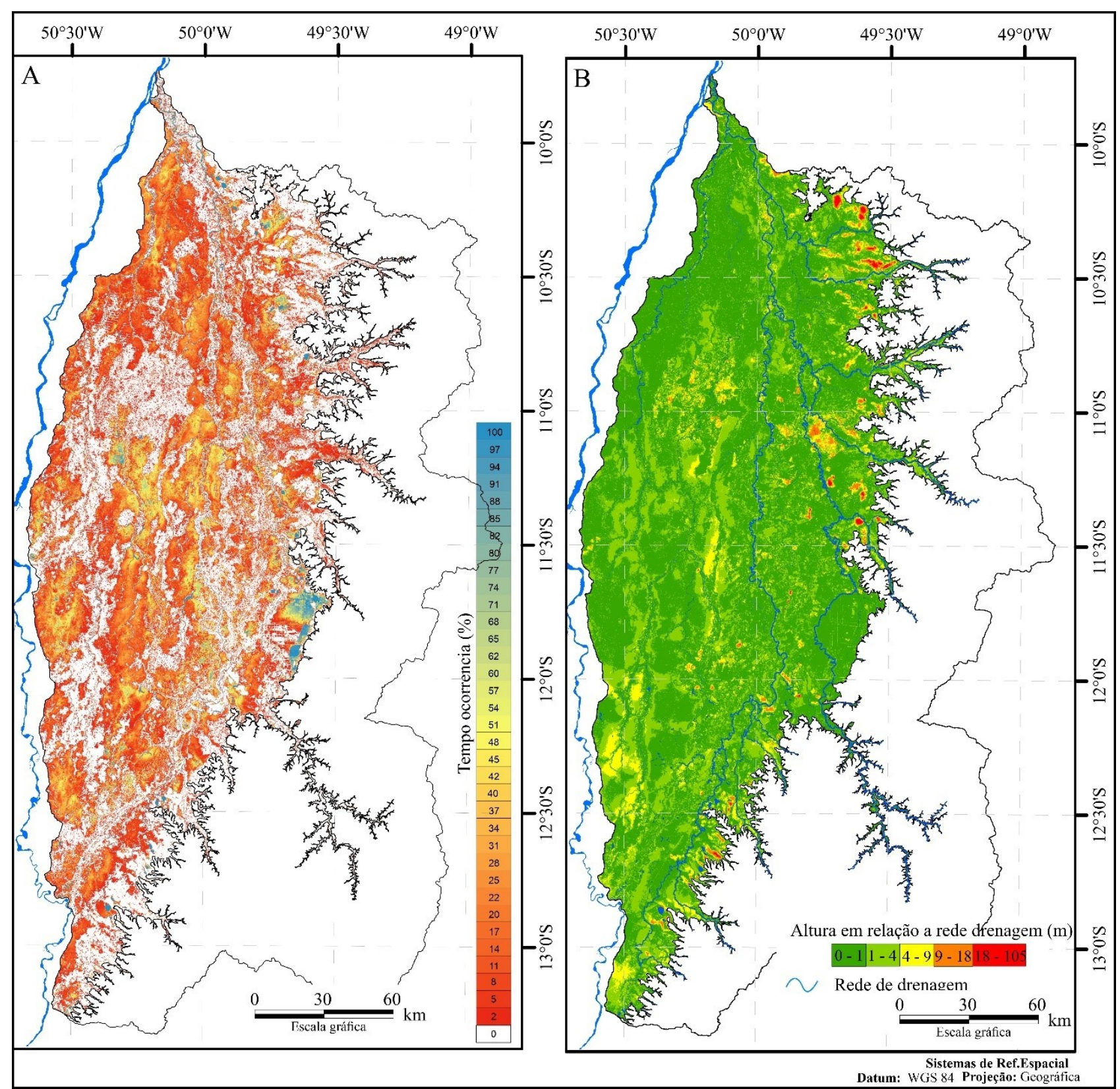

Figura 7 - A) mapa de percentual de tempo (anos) da ocorrência da inundação na área de estudo. B) Mapa de altura em relação a rede de drenagem da zona deposicional do rio Javaés. Fonte: os autores.

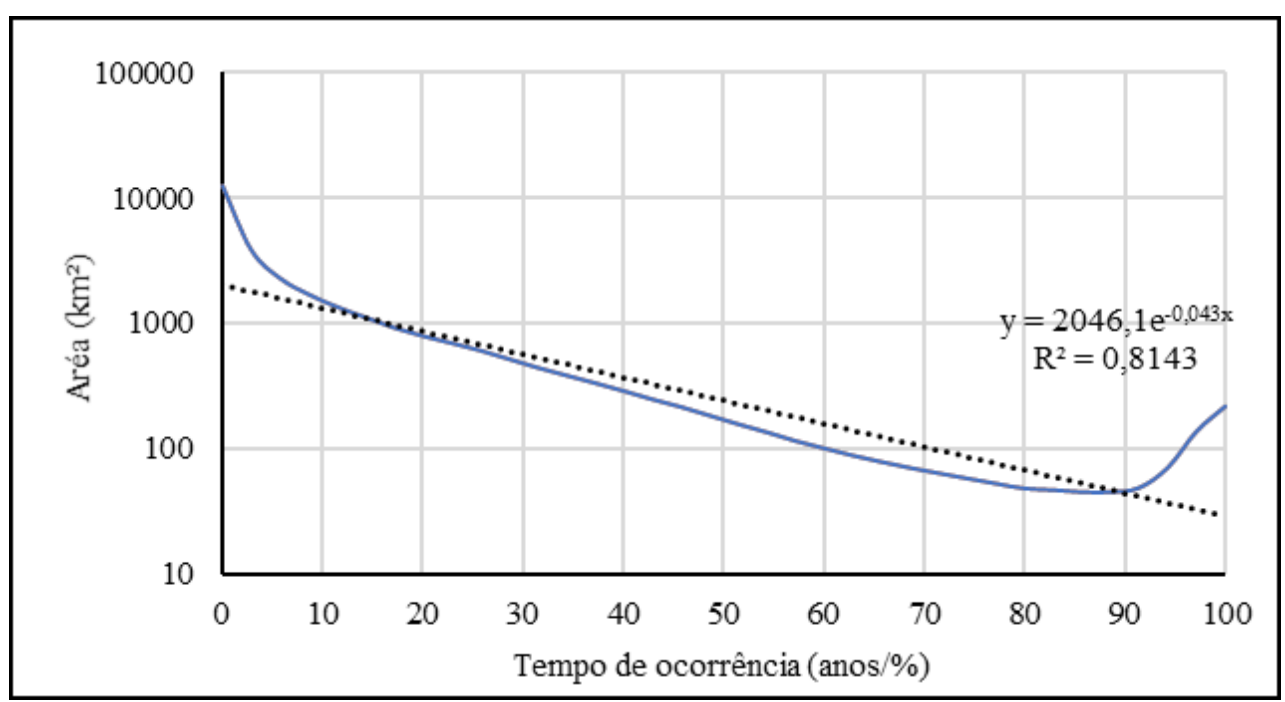

Figura 8 - Curva de distribuição de área em função da ocorrência de inundação. Fonte: os autores. 


\subsection{Dinâmica temporal da precipitação e vazão}

Conforme figura 9, a observação dos valores de precipitação anual por meio dos gráficos de boxplot indica que a distribuição geral é predominantemente assimétrica ao longo de cada ano, com concentração dos dados (75\%) entre 0 e 350 mm mensais. Desta forma, é observada que a dispersão dos pontos (meses) é influenciada pela sazonalidade climática, que segmenta em grupos de meses chuvosos (azuis), secos (laranja-vermelho) e de transição (amarelos). Os valores de centralidade (média e mediana) são bastante próximos em quase todos os anos.

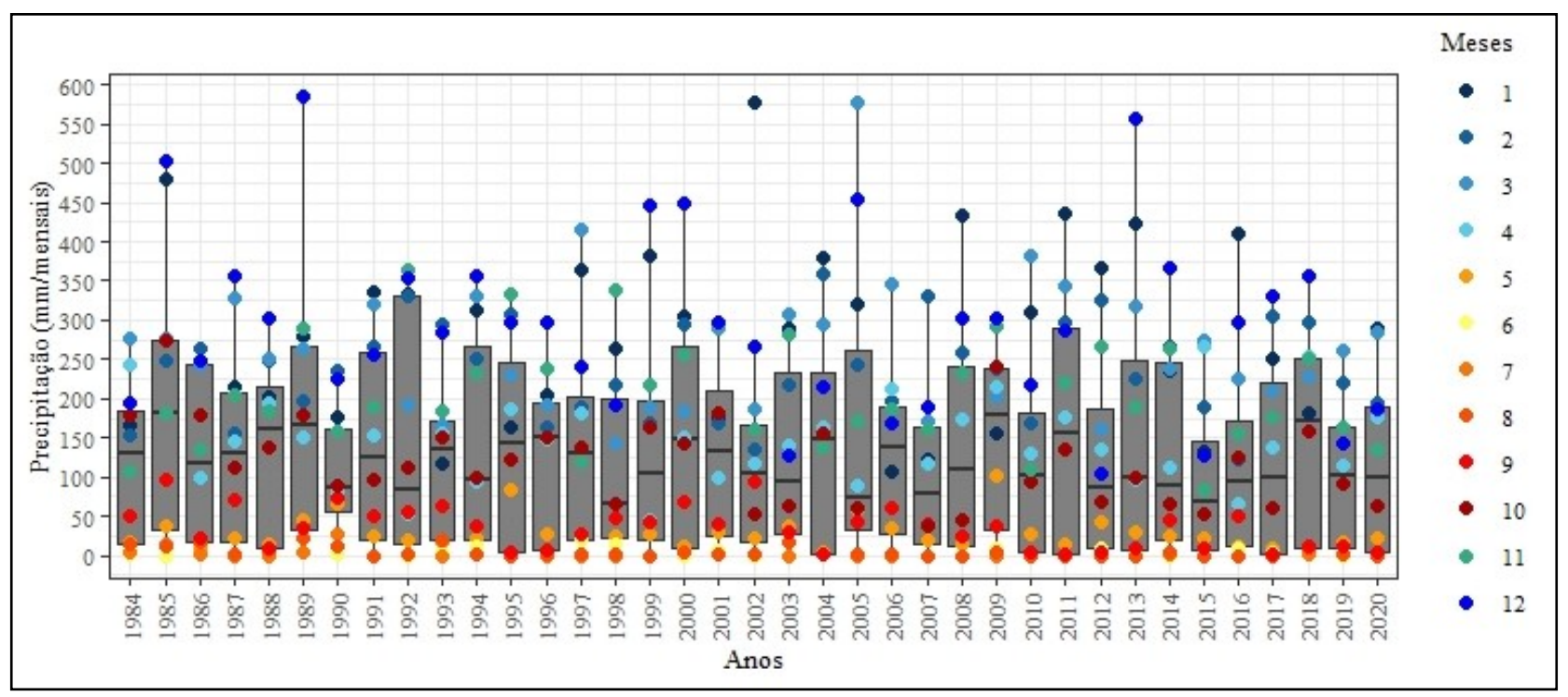

Figura 9 - Gráficos de boxplots com a distribuição anual dos valores de precipitação na área de estudo. Fonte: os autores.

Os dados dispostos no quarto quartil nos boxplots indicam alta variação em relação as posições da mediana, com volumes superiores mais recorrente em dezembro (12). Assim, os valores máximos apresentam uma constância entre 350 e $500 \mathrm{~mm}$ mensais, com destaque e alternância anual entre os meses dezembro, fevereiro, janeiro e abril. Os anos 1986, 1989, 1997, 1999, 2005 e 2013 apresentam meses com alta precipitação acumulada com valores distantes das médias e medianas. Destaca-se com maiores valores, o outlier de janeiro de 2002 com $576 \mathrm{~mm} / \mathrm{mensais,} \mathrm{o} \mathrm{que} \mathrm{equivale}$ a 36\% do acumulado desse ano. Dezembro de 1989 apresentou o maior volume de chuvas (589 $\mathrm{mm}$ ) na série avaliada, seguido de março de 2005 (576 mm/mensais). O primeiro quartil reúne valores de precipitação entre 0 e $20 \mathrm{~mm}$ mensais, com destaque para os meses entre junho a outubro (Figura 9). O ano de 1990 apresenta uma forte redução na amplitude de precipitação, com média de $100 \mathrm{~mm}$ e mediana de $90 \mathrm{~mm}$ mensais, com um total acumulado de $1.200 \mathrm{~mm}$ anuais.

Os dados de vazão cotados nos hidrogramas na figura 10, registram estimativas entre janeiro de 1984 e julho de 2020 de médias mensais (em m³/s). A estação Barreira do Pequi está localizada 
no rio Javaés em um ponto estratégico de travessia para Ilha do Bananal, com largura do canal com média de $130 \mathrm{~m}$. Situa-se a aproximadamente a $100 \mathrm{~km}$ do ponto de avulsão do rio Araguaia que forma seu braço menor, e a 9,5 km a jusante da foz do rio Água Fria, em cota altimétrica de $195 \mathrm{~m}$. A cota média do nível do rio possui variação anual de $10 \mathrm{~cm}$ nos períodos de seca até quatro metros nos picos de cheia em março.

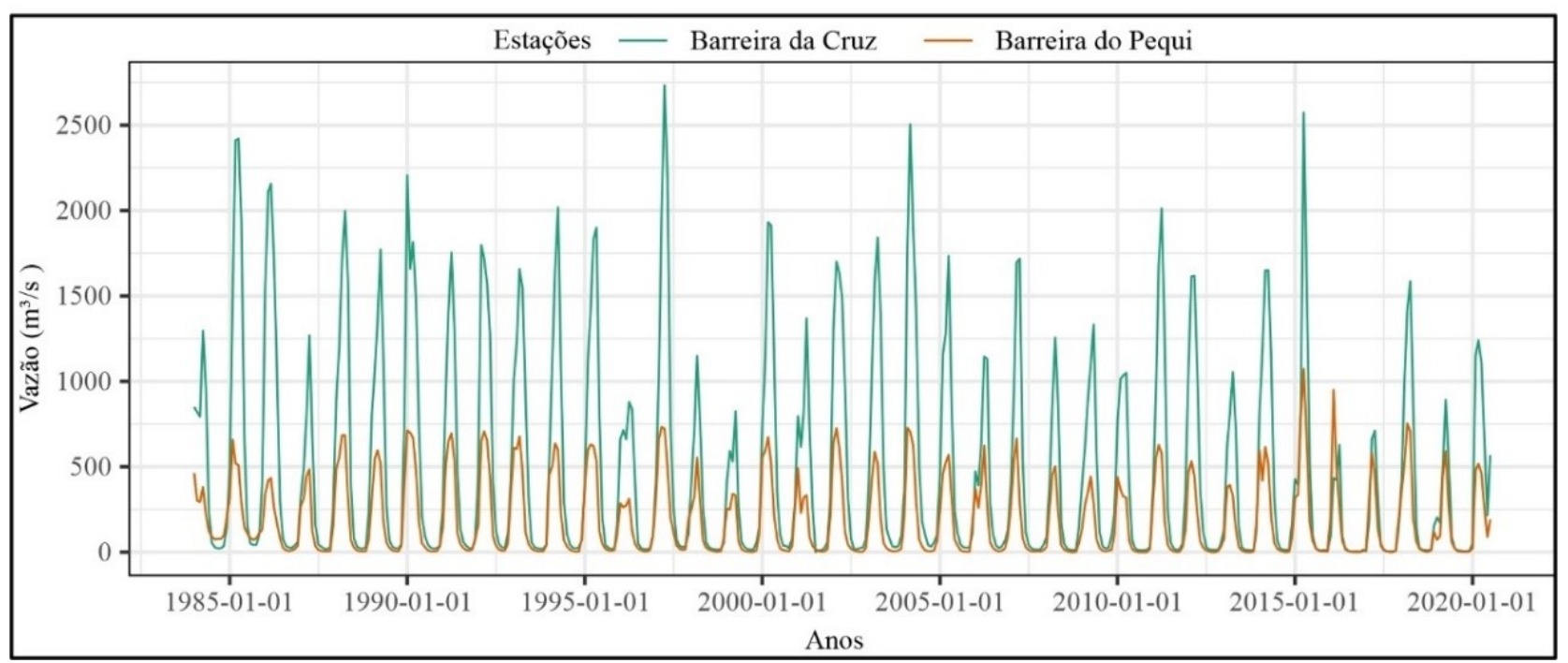

Figura 10 - Hidrogramas com a vazão média mensal de estações no rio Javaés. Fonte: os autores.

A estação Barreira do Pequi registra dados fluviométricos do canal principal de $7^{\circ}$ ordem na classificação de Strahler, formado pela confluência de tributários predominantes da margem esquerda da bacia do rio Javaés, um segmento de canal reativado que se junta com os rios Verde e Água Fria (Figura 1). Os dados plotados na figura 10 indicam que a vazão média mensal nesta estação apresenta frequência anual similar entre 1985 e 1995, com amplitude média de $650 \mathrm{~m}^{3} / \mathrm{s}$. Algumas distribuições anuais achatadas interrompem esta sequência de instabilidade média, como no ano de 1996 com amplitude mais reduzida na série histórica $\left(309 \mathrm{~m}^{3} / \mathrm{s}\right)$. O pico mais elevado na série foi em março de $1997 \mathrm{com} 729$ m³/s. Os anos de 1998 e 1999 indicam valores de pico de vazão abaixo de $500 \mathrm{~m}^{3} / \mathrm{s}$. a partir de 2000 a faixa de amplitude volta ao padrão anterior a 1995, porém entre 2007 e 2010 é reduzida para valores inferiores a $500 \mathrm{~m}^{3} / \mathrm{s}$. Uma dinâmica similar é indicada entre 2011 e 2020, com 2013 com menor redução na amplitude 393 m³.s.

A Barreira da Cruz está localizada a jusante da Barreira do Pequi no rio Javaés, em cota topográfica de $180 \mathrm{~m}$ em relação ao nível do mar, a aproximadamente $100 \mathrm{~m}$ a jusante da foz do rio Formoso, principal tributário da área de estudo que representa mais de dois terços dos sistemas de nascentes. Nesta posição o rio Javaés é de $8^{\circ}$ ordem com uma largura média de $200 \mathrm{~m}$, e apresenta uma variação da cota média entre $1 \mathrm{~m}$ no período de estiagem a $6,5 \mathrm{~m}$ no nível de margens plenas. $\mathrm{O}$ hidrograma de vazão da Barreira da Cruz apresenta por padrão picos agudos monomodais, com rápida 
elevação nos níveis do rio Javaés entre janeiro e abril, enquanto que na Barreira do Pequi os picos são mais abaulados (Figura 4A), podendo ocorrer picos bimodais com amplitude inferior a $1000 \mathrm{~m}^{3} / \mathrm{s}$ (Figura 10). A amplitude dos valores de vazão plotados no hidrograma da Barreia da Cruz é em média duas vezes superior ao da Barreira do Pequi. Elevação da vazão só é perceptível a partir de janeiro, em correspondência com a maior distribuição de chuvas na bacia (Figura 4). Em média os dados indicam que a frequência de picos de cheia do rio é maior em abril (posterior aos picos de inundação). Picos superiores a 2000 m³/s são mais recorrentes entre os anos de 1984 e 1995 , com uma média mensal de $617 \mathrm{~m}^{3} / \mathrm{s}$, com destaque para março e abril de 1985 , com vazão média de 2.400 $\mathrm{m}^{3} / \mathrm{s}$. O ano de 1997 também se destaca nesta estação com maior pico de cheia em abril com 2.732 $\mathrm{m}^{3} / \mathrm{s}$. Os anos de 2014, 2016, 2017 e 2019 apresentam níveis de cheia inferiores a 900 m³/s.

\section{DISCUSSÃO}

\subsection{Avaliação de tendências e correlação em séries temporais}

A análise do conjunto de dados em séries temporais da inundação anual e das médias mensais da precipitação e vazão indicam tendência de redução de área e volume na série histórica (19842020), situação que se correlaciona em grande parte a alguns resultados indicados em trabalhos no contexto do Cerrado, como o mapeamento de inundação de Hamilton et al (2002), e as estimativas da variabilidade da precipitação por Marcuzzo et al. (2012), Campos e Chaves (2020) e Neto et al. (2021). Desta forma buscou-se testar as hipóteses estatísticas para verificar a presença ou ausência de tendência nos dados descritos, por meio do teste Mann-Kendall e de sua versão adaptada para dados sazonais, adotando uma significância de $\mathrm{p}<0,05$.

O teste de Mann-kendall simples foi aplicado sobre os dados da série de inundação, tendo em vista que os resultados de área inundada foram interpretados a partir de imagens geradas em uma mesma estação climática. $O$ teste indicou um valor de $\mathrm{p}$-valor $<0,05$, apontando para a rejeição da hipótese nula e a confirmação de presença de tendência do tipo decrescente, com valor de $\mathrm{S}$ negativo (-204) e tau de -0,32 (Figura 11). Hamilton et al. (2002) mapeou as principais áreas de inundação na américa do Sul, incluindo toda a planície do Araguaia, a partir do uso de produtos do satélite SMMR Nimbus-7, imagens geradas entre 1979 a 1987. Neste trabalho também é indicado empiricamente a presença de tendência com redução de amplitude de inundações máximas na planície do Bananal, com taxas mais regulares a partir de 1980, ocorrendo menores valores no final dessa década. 


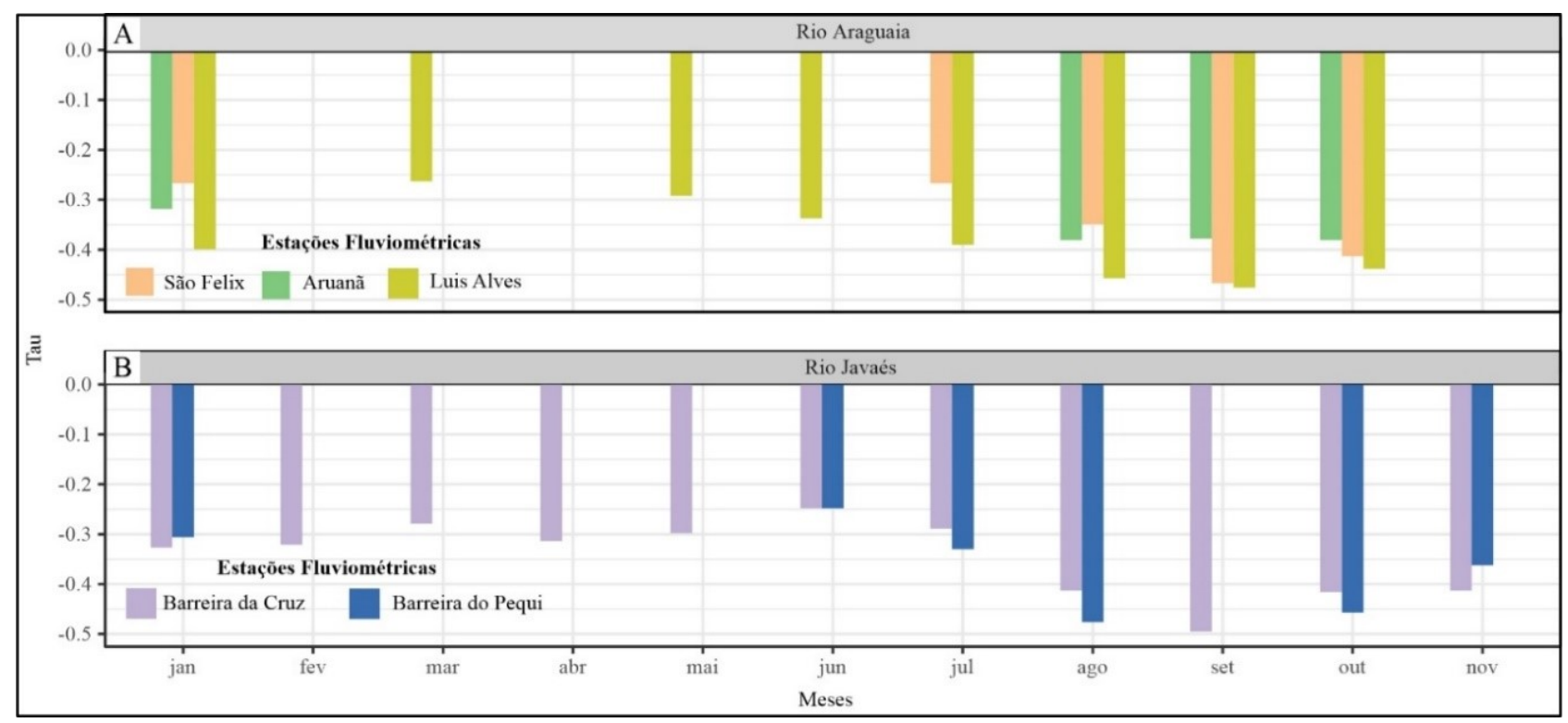

Figura 11 - Distribuição do valores de tau do teste estatístico sazonal de Mann-Kendall, sobre variaveis vazão; A) bacia do rio Araguaia; B) Bacia do rio Javaés. Fonte: os autores.

Ao comparar com os demais ambientes, Hamilton et al. (2002) indicam que ocorre maior variabilidade de áreas inundadas na planície do Araguaia/Bananal e nas planícies de Roraima ao longo dos anos, e estimaram que a área máxima de inundação é de $55.000 \mathrm{~km}^{2}$. No aspecto metodológico é necessário ponderar que apesar das características radiométricas do sensor de radar favorecerem a identificação dos alvos em zonas tropicais, perpassando obstruções atmosféricas periódicas (CARBONNEAU; PIÉGAY, 2012; MENESES, 2012; EVANS; COSTA, 2013; UDDIN et al., 2019), a baixa resolução espacial das imagens utilizadas pode reduzir a capacidade de identificação de áreas com menor abrangência espacial, a exemplo de zonas palustre e lacustre em ambientes de lagoas, comuns na região do médio Araguaia (MORAIS et al., 2005). Iron et al. (2016) também mapearam a dinâmica de inundação do alto e médio Araguaia através da classificação de imagens do sensor TM do LANDSAT 5, e identificaram uma área de inundação com $88.119 \mathrm{~km}^{2}$. Os autores apontam a maior frequência de áreas inundadas próximas a zonas aluviais do tronco principal, com uma cobertura úmida reduzida para até 3,3\% na fase de seca.

O teste de Mann-kendall ajustado a condição de sazonalidade da série temporal de pluviometria indicou um valor de $\mathrm{p}>0,05$ entre os meses de janeiro e junho, e também em novembro e dezembro, o que sugere a ausência de tendência na série histórica nos meses com chuvas mais regulares. Valores de $\mathrm{p}<0,05$ são observados entre os meses de julho e outubro, com destaque para o índice tau de agosto de $-0,32$ e setembro com -0,31. Estes resultados mais expressivos em meses considerados "secos" podem ser melhor explorados quando se considera alguns aspectos na pluviosidade da região: Conforme Neto et al. (2021), aproximadamente $90 \%$ da precipitação acumulada anualmente no domínio do Cerrado é registrada entre outubro e abril; o restante é complementado por episódios de pluviometria esporádica em meio ao ciclo de estiagem (entre junho 
e início de setembro). Desta forma, os dados de precipitação avaliados indicam picos entre 10 e 30 $\mathrm{mm} / \mathrm{mensais} \mathrm{nos} \mathrm{meses} \mathrm{de} \mathrm{junho} \mathrm{e} \mathrm{julho,} \mathrm{concentrados} \mathrm{nos} \mathrm{anos} \mathrm{finais} \mathrm{da} \mathrm{década} \mathrm{de} \mathrm{1980;} \mathrm{nota-se}$ queda acentuada a partir da década de 1990 e anos posteriores, com amplitudes inferiores a 5 $\mathrm{mm} /$ mensais. A tendência regressiva detectada nos meses de setembro e outubro pode ter relação com aumento da estiagem nas últimas décadas (SILAS, 2016). A partir do teste espacial de Mann-Kendall, Espinoza et al. (2019) evidenciam esta situação de prolongamento do tempo de estiagem no sudoeste da Amazônia legal, com correspondência espacial com a ilha do Bananal, por meio da descrição de séries diária com precipitação inferior a 1 mm entre 1981 e 2017.

Indiretamente envolvendo a área de estudo, outros trabalhos avaliaram a dinâmica das chuvas por meio de dados de estações climatológicas no Bioma Cerrado. Destaca-se a pesquisa de Marcuzzo et al. (2015) que selecionaram entre 150 estações, 22 com dados consistidos de médias mensais de 30 anos (de 1977 a 2006). Por meio de regressão linear simples sobre séries temporais organizadas por meses, identificou-se maior coeficiente de redução da precipitação em janeiro e maior crescimento em março. Já Campos e Chaves (2020) por meio do teste de Mann-Kendall simples, analisaram séries temporais de precipitação de 125 estações distribuídas no Cerrado, e 1g/, com aumento em $25 \%$. Os autores estimaram que entre 1977 e 2010, ocorre uma redução em média de $8 \%$ das chuvas no Cerrado, com 14\% dos dados com tendência negativa com significância a nível de 5\%.

Neto et al. (2021), de maneira similar a Campos e Chaves (2020), usaram o teste simples de Kendall por série temporal anual, especificamente para a seleção de dados sem tendência, para serem utilizados na espacialização dos dados pluviométricos. Neste trabalho foram analisadas 93 séries temporais de estações no Tocantins e em estados circunvizinhos. 14 séries apresentaram tendências negativas ou positivas. Destaca-se que este estudo não identificou tendência nos dados das estações situadas na bacia do rio Javaés ou na região do vale do Araguaia. Neste aspecto, conforme Blain (2010), ao avaliar tendências mensais de precipitação em série histórica, pontua que o teste simples de Kendall apresenta melhor desempenho quando a amostragem em série é independente. conforme Onoz e Bayazit (2012), é importante observar que o teste simples de Kendall não é recomendado quando se detecta dependência serial, fator que geralmente é recorrente em séries hidrológicas e climáticas, e que podem aumentar a probabilidade de detecção de tendência não significativa e erro do tipo I (HIRSCH; SLACK, 1984).

O teste de tendência sazonal de Kendall aplicado aos dados de vazão na Barreira do Pequi apresentou significância de $\mathrm{P}<0,05$ para os meses de janeiro e entre julho e novembro; já na Barreira da Cruz a tendência significativa foi indicada para os meses entre janeiro e abril, e entre junho e novembro (Figura 11B). Reduções mais acentuadas ocorrem na Barreira da Cruz, com valores de tau com variação negativa de $-0,3$ entre janeiro e maio e regressão gradativa entre junho $(-0,27)$ e setembro $(-0,5)$. 
Testes de Kendall Sazonal também foram calculados para as estações no rio Araguaia mais próximas da bacia do rio Javaés, e apresentaram valores de significância de $\mathrm{P}<0,05$, confirmando tendências negativas para alguns meses (Figura 11B). As três estações no Araguaia apresentam níveis de regressão em janeiro e nos meses de estiagem. A estação de Luís Alves tem a maior quantidade de meses com tendência regressiva e os maiores valores no grupo, com destaque de tendência regressiva entre maio e outubro. Desta forma, nota-se que os valores de tau encontrados no rio Araguaia são similares aos da bacia do rio Javaés, e apresentam elevação nas estações mais a jusante, junto a planície do Bananal. Desta forma, é possível sugerir que existe uma tendência regional na regressão da vazão na região do médio Araguaia, com redução nas descargas nos últimos 35 anos, e assim como na precipitação, pode ter relação com prolongamento da estiagem sazonal.

Os resultados dos modelos de regressão utilizados para o preenchimento de vazios nas séries temporais (Figura 12) também permitiu interpretar se a dinâmica hidrológica nas estações do rio Araguaia apresenta correspondência linear com os dados de estações no rio Javaés. Os dados da matriz de correlação na figura 12 indicam que as variáveis (estações) apresentam valores significativos com valor de $\mathrm{P}<0,05$ (asteriscos ***) com coeficientes de correlação forte entre as estações no rio Araguaia (Aruanã, Luís Alves e São Felix) no rio Javaés (Barreira do Pequi e Barreira da Cruz).

Os resultados sistematizados no gráfico de Correlograma foram organizados em sequência conforme a proximidade geográfica, sendo a estação Aruanã localizada mais a montante e Barreira da Cruz mais a jusante. Os resultados dos coeficientes de correlação indicam que os valores de R são superiores a 0,8 entre as variáveis do rio Araguaia, e $\mathrm{R}=0,89$ entre Barreira da Cruz e Barreira do Pequi. Os dados da estação de Aruanã apresentou menores coeficientes de correlação com as estações do Javaés ( $\mathrm{R}=0,79, \mathrm{R}=0,63)$. As regressões calculadas na relação entre dados de São Felix e Luís Alves com as estações do Javaés apresentam valores de $\mathrm{R}$ superiores a 0,8 .

Apesar do título popular de "braço menor do Araguaia" (LATRUBESSE; STEVAUX, 2007), a análise de dados da rede de drenagem indica que o sistema Javaés possui uma organização de bacia hidrográfica regional, e mantem uma independência frente ao sistema Araguaia. Essa condição pode ser afirmada com base na análise da rede de drenagem, que apresenta conectividade longitudinal bem definida e sistemas fluviais de perfis já maturados como o rio Formoso, estruturados em rochas paleoproterozóicas do cinturão Araguaia. Essa configuração estrutural da bacia hidrográfica garante o fornecimento da maior parte dos débitos fluviais e sedimentares para o nível de base do Javaés (SANTOS; MORAIS, 2017). Desta forma as séries de imagens de satélites avaliadas indicam que a contribuição hidrossedimentológica da principal conexão anômala entre o rio Araguaia e Javaés é restrita e regulada pela dinâmica de cheia, sendo inoperante na maior parte do ano. Neste sentido, os dados indicam que a maior parte das áreas de inundação mapeadas correspondem a ambientes 
geomorfológicos intrínsecos a dinâmica das planícies do rio Javaés, com diferentes controles de estruturas de paisagem (palimpsesto), promovendo a conectividade ou restrição de fluxos entre compartimentos.

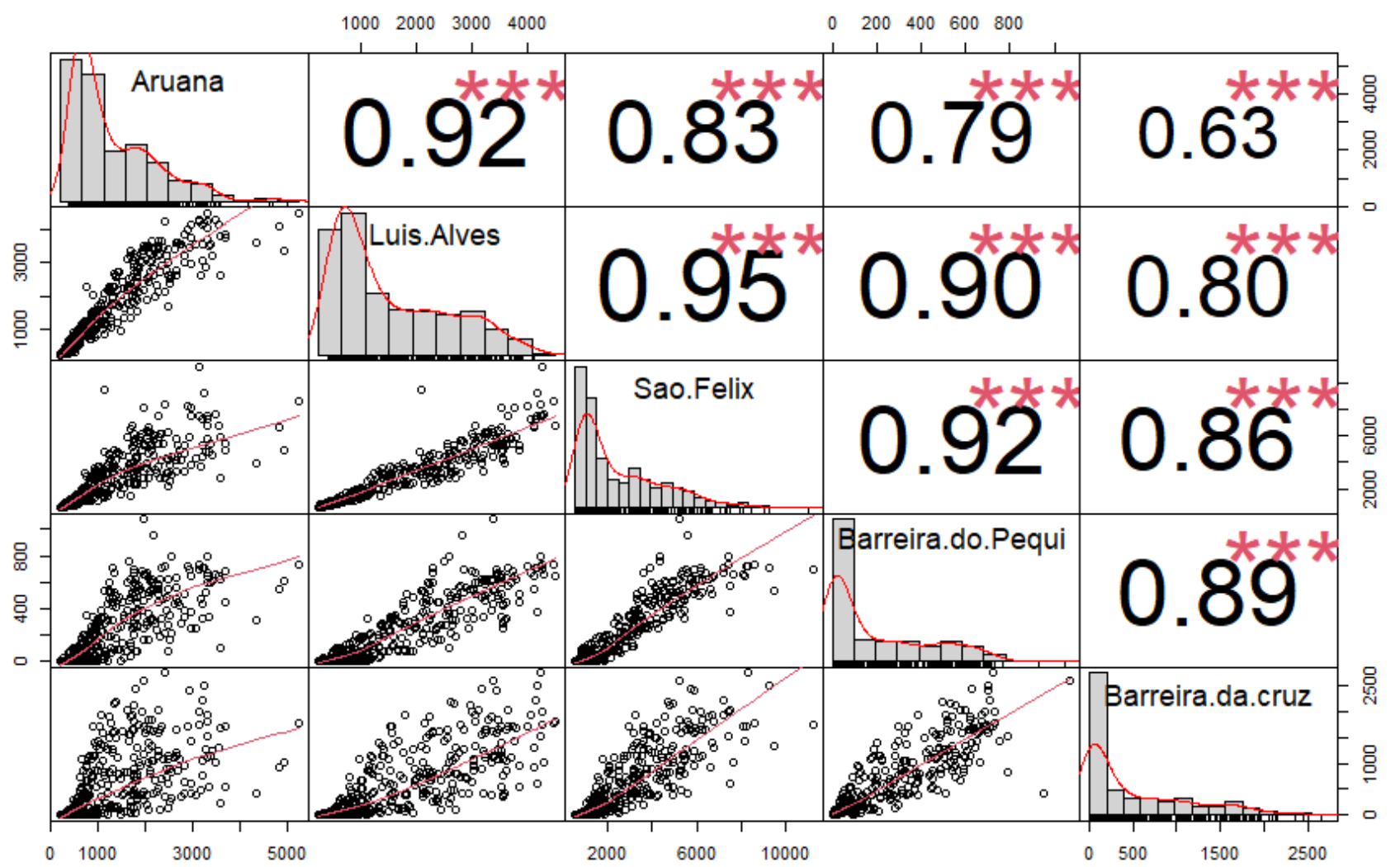

Figura 12 - Correlograma de dados de vazão média mensal de estações no rio Araguaia e rio Javaés.

Fonte: os autores.

\subsection{Controles geomorfológicos sobre a dinâmica de inundação}

No interior da ilha do Bananal, o rio Riozinho exibe longos trechos de rio meandrante intercalados por segmentos retilíneos encaixados em paleocanais do rio Araguaia, com uma conectividade lateral condicionada pela sazonalidade dos pulsos de inundação. Mamede et al. (1981) descrevem a presença de fenômeno de inversão da direção de fluxo durante as cheias anuais neste rio, indicando o processo de represamento das águas na foz com o rio Javaés. Porém os dados levantados na presente pesquisa não permitiram confirmar esta situação. Nas dependências do Parque Nacional do Araguaia (sítio Ramsar) (Figura 13), a dinâmica de inundação da planície do Riozinho se destaca das demais porções na área de estudo, com uma extensa penetração horizontal da fase de inundação, ocorrendo entre 30 e 50\% do tempo analisado. 


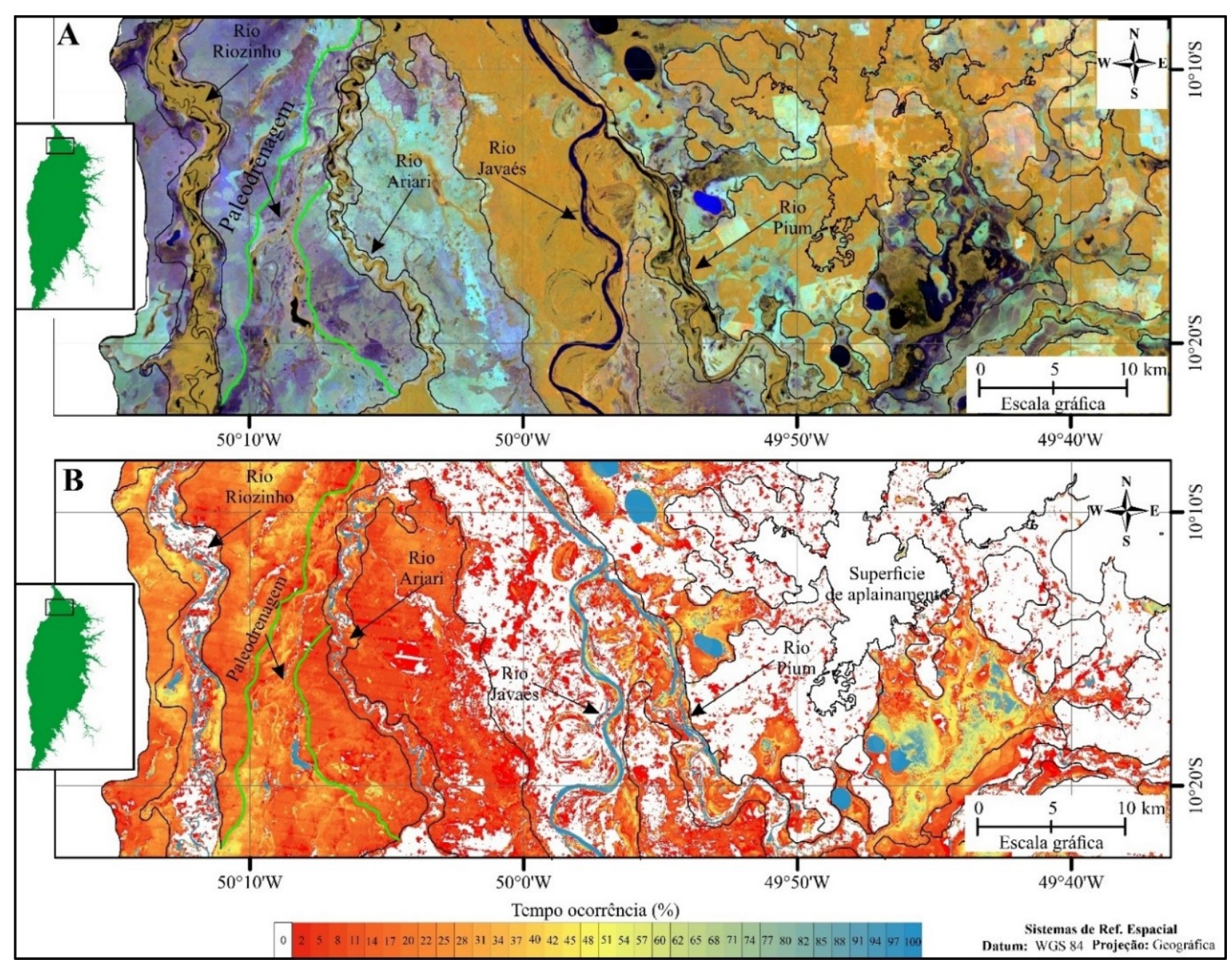

Figura 13 - A) Composição colorida (RED; SWIR1; NIR) de bandas com ND de médias entre 1985 e 2020 do mês de março (imagens LANDSAT). B) Ocorrência anual (\%) da inundação na porção norte do baixo curso do rio Javaés.

Fonte: os autores.

Na figura 13 é possível notar que a inundação sazonal ocupa as mediações de paleodrenagens, com conexão temporária ao rio Arari com o rio Riozinho. Os documentos cartográficos indicam drenagens estreitas com diferentes extensões denominadas na região como 'esgotos', e conforme a identificação de Santos e Morais (2017), correspondem a paleocanais reativados que se conectam anarquicamente, transmitindo os fluxos de vazante entre rios e lagoas, com aparente elementos de fisiografia aluvial ativa (diques, feições deposicionais e conjuntos de mata ciliares). Estes canais secundários são, portanto, "nutridos" pelas fases de cheias monomodais, promovendo a "pirataria" de águas entre sistemas maiores como os rios Riozinho, Araguaia e Javaés (ZAPROWSKI, et al. 2002).

Ao longo das margens dos principais rios o corredor de vegetação se destaca (Figura 13A), com ocorrência fracionada de manchas de inundação ou lagos na planície aluvial (Figura 13B). Os tons negros e azuis observados na composição da figura 13A, correspondem a ambientes lênticos e com fluxo ativo nos rios, enquanto que as variações de tons violetas equivalem a áreas com diferentes níveis de saturação hídrica em superfície. Os tons amarelos indicam vegetação densa de porte arbóreo. 
A resposta da vegetação densa nestas faixas do infravermelho indica altos valores de reflectância $(<0,6)$, e conforme o princípio do comportamento espectral dos alvos em superfície (JESEN, EPIPHANIO, 2009; BARBOSA, 2019), o predomínio de dossel densos e elevados de Mata Ciliar, Floresta Estacional no interior da ilha do Bananal e Floresta ombrófila densa aluvial na porção norte junto ao Parque Estadual do Cantão (Figura 13), pode ter reduzido a capacidade dos sensores LANDSAT de detecção de águas superficiais. Conforme o modelo de inundação derivado do SWIR1, as várzeas sazonais foram identificadas com maior recorrência nas planícies de interior ou planos de inundação, ambientes com maior correspondência com a vegetação de baixo porte, como gramíneas e grupos arbustivos, o que pode ter favorecido a sensibilidade de captação desses ambientes inundados (UMETSU et al., 2011; VALENTE et al., 2013; DENG et al., 2014).

\section{CONSIDERAÇÕES FINAIS}

O presente trabalho buscou analisar a variabilidade espacial e temporal da dinâmica de inundação, considerando possíveis níveis de influência, controle e tendência de variáveis climáticas sobre processos hidrogemorfológicos na zona deposicional do rio Javaés. Desta forma, a janela temporal com base em séries temporais de 1984 a 2020, derivadas de produtos de Sensoriamento Remoto e de estações fluviométricas, possibilitou considerar que:

- Os dados interpretados a partir do fatiamento de imagens do SWIR1 indicaram valores superiores de área inundada, quando comparado com abordagens de razão de bandas, o que resultou em um modelo mais ajustado com as médias de dinâmica mensal da precipitação e descarga fluvial. É possível considerar que os índices NDWI e MNDWI não apresentaram respostas adequadas para o contexto ambiental estudado, tendo em vista: 1) a baixa sensibilidade demostrada para a identificação de água na planície durante a fase de inundação, mesmo em locais de baixa cobertura vegetal; 2) a baixa variabilidade entre os meses, com exceção de março, o que indica que esses métodos são mais eficientes em ambientes de água aberta.

- Os dados do TerraClimate permitem considerar que a sazonalidade climática controla diretamente o andamento dos processos hidrogemorfológicos nos rios e compartimentos de planícies, por meio de ciclo de intermitência sobre a maior parte dos ambientes e da rede de drenagem (entre 4 e 5 meses); a redução da precipitação e elevação da evapotranspiração ocorre em menos de dois meses, resultando em rápidos ajustes de descontinuidades laterais e longitudinais.

A paisagem está sujeita a uma longa sequência de déficit hídrico elevado. Desta forma entre 50 e $60 \%$ do período de chuvas ocorre a fase de recuperação dos fluxos fluviais, seguido de cheias curtas dos rios e com apenas 2 meses de permanência de estado úmido nos planos de inundação. Assim como observado no Pantanal, a vegetação de porte arbustiva é atingida pela seca, 
principalmente no interior da ilha do Bananal, e torna-se altamente vulnerável a formação de grandes incêndios.

- O teste de sazonal de Man-Kendall otimizou a detecção de tendência através da abordagem mensal, demonstrando que os meses sujeitos a estiagem têm sido mais afetados por possíveis ajustes climáticos nos últimos 35 anos, por meio da redução da precipitação no início da estação chuvosa, situação também observada em parte na porção sul da região amazônica.

- As séries históricas de vazão média a montante e jusante no rio Javaés também indicam reduções significativas em praticamente todos os meses no volume médio de vazão, principalmente em meses de estiagem, com destaque para a estação Barreira da Cruz. Esta situação deve ser melhor investigada em outros trabalhos, tendo em vista a conjuntura histórica de uso dos recursos hídricos na bacia hidrográfica, em plena expansão. Desta forma, os dados apresentam alta correlação com as tendências de redução, observadas em outras localidades na bacia do rio Araguaia.

- O modelo de frequência e ocorrência de inundação permitem observar que a porção estudada da Ilha do Bananal concentra as maiores áreas de inundação, com dois padrões distintos de espacialização do fenômeno. Destaca-se neste compartimento:

1) Características sedimentares (fácies areno argilosa), geomórficas (baixa declividade) e morfopedológicas (Plintossolos Argilúvicos) da porção cento sul, condicionam em conjunto aos ambientes sem sistema de drenagem plenamente desenvolvido, com inundação sazonal gerada principalmente pela saturação de horizontes superficiais dos solos, devido a presença de horizontes concrecionários nas camadas subsuperficiais; desta maneira, mesmo localizada em altura similar ao dos rios, os planos de inundação possuem uma conectividade parcialmente bloqueada por paleodiques na porção centro sul da ilha;

2) na porção centro norte da ilha, com destaque para o rio Riozinho, as zonas de inundação estão distribuídas entre faixas aluviais em mesmo nível que a drenagem, porém as paleodrenagens anarquicamente estruturadas e reativadas realizam o intercâmbio de fluxos entre zonas aluviais e entre zonas sazonalmente inundadas (Figura 13B).

\section{AGRADECIMENTOS}

Os autores agradecem à Coordenação para Aperfeiçoamento de Pessoal de Ensino Superior (CAPES) pela bolsa de doutorado concedida ao primeiro autor. 


\section{REFERÊNCIAS}

ABATZOGLOU, J. T.; DOBROWSKI, S. Z.; PARKS, S. A.; HEGEWISCH, K. C. TerraClimate, a high-resolution global dataset of monthly climate and climatic water balance from 19582015. Scientific data, v. 5, n. 1, p. 1-12, 2018.

ACHARYA, T. D.; SUBEDI, A.; LEE, D. H. Evaluation of water indices for surface water extraction in a Landsat 8 scene of Nepal. Sensors, v. 18, n. 8, p. 2580, 2018.

ASSINE, M. L.; SOARES, P. C. Quaternary of the Pantanal, west-central Brazil. Quaternary International, v. 114, n. 1, p. 23-34, 2004.

BARBIER, E. B.; ACREMAN, M.; KNOWLER, D. Economic valuation of wetlands: a guide for policy makers and planners. Gland: Ramsar Convention Bureau. 1997.

BARBOSA, C. C. Princípios Físicos do Sensoriamento Remoto Aquático. IN: BARBOSA, C. C. F.; DE MORAES NOVO, E. M. L.; MARÇOTINS, V. S. (Ed.) Introdução ao Sensoriamento Remoto de Sistemas Aquáticos: princípios e aplicações. Vol 1, INPE - Instituto Nacional de Pesquisas Espaciais, 2019.

BAYER, M.; ASSIS, P. C.; SUIZU, T. M.; GOMES, M. C. Mudança no uso e cobertura da terra na bacia hidrográfica do rio Araguaia e seus reflexos nos recursos hídricos, o trecho médio do rio Araguaia em Goiás. Confins. Revue franco-brésilienne de géographie/Revista franco-brasilera de geografia, v. 48, 2020.

BAYER, M.; ZANCOPÉ, M. H. C. Ambientes sedimentares da Planície aluvial do Rio Araguaia. Revista Brasileira de Geomorfologia, Brasília, v.15, n.02, p.203-220, 2014.

BERNHARDT, C. E.; HORTON, B. P.; STANLEY, J.-D. Nile Delta vegetation response to Holocene climate variability. Geology, v. 40, n. 7, p. 615-618, 2012.

BLAIN, G. C. Detecção de tendências monótonas em séries mensais de precipitação pluvial do Estado de São Paulo. Bragantia, v. 69, n. 4, p. 1027-1033, 2010.

BROOKS, N. Cultural responses to aridity in the Middle Holocene and increased social complexity. Quaternary International, v. 151, n. 1, p. 29-49, 2006.

BURN, J. W. A river in drought: Consequences of a low Nile at the end of the Old Kingdom. Environment and Ecology Research, v. 6, n. 5, p. 446-460, 2018.

CAMPOS, J. D. O.; CHAVES, H. M. L. Tendências e Variabilidades nas Séries Históricas de Precipitação Mensal e Anual no Bioma Cerrado no Período 1977-2010. Revista Brasileira de Meteorologia, v. 35, n. 1, p. 157-169, 2020.

CARBONNEAU, P.; PIÉGAY, H. Fluvial remote sensing for science and management. John Wiley \& Sons, 2012.

DAVIDSON, N. C.; FLUET-CHOUINARD, E.; FINLAYSON, C. M. Global extent and distribution of wetlands: trends and issues. Marine and Freshwater Research, v. 69, n. 4, p. 620-627, 2018. 
DENG, F.; WANG, X.; CAI, X.; LI, E.; JIANG, L.; LI, H.; YAN, R. Analysis of the relationship between inundation frequency and wetland vegetation in Dongting Lake using remote sensing data. Ecohydrology, v. 7, n. 2, p. 717-726, 2014.

ESPINOZA, J. C.; RONCHAIL, J.; MARENGO, J. A.; SEGURA, H. Contrasting North-South changes in Amazon wet-day and dry-day frequency and related atmospheric features (19812017). Climate Dynamics, v. 52, n.9, p. 5413-5430,2019.

EVANS, T. L.; COSTA, M. Landcover classification of the Lower Nhecolândia subregion of the Brazilian Pantanal Wetlands using ALOS/PALSAR, RADARSAT-2 and ENVISAT/ASAR imagery. Remote Sensing of Environment, v. 128, p. 118-137, 2013.

FEYISA, G. L.; MEILBY, H.; FENSHOLT, R.; PROUD, S. R. Automated Water Extraction Index: A new technique for surface water mapping using Landsat imagery. Remote Sensing of Environment, v. 140, p. 23-35, 2014.

FINLAYSON, C. M.; DAVIDSON, N. C.; SPIERS, A. G.; STEVENSON, N. J. Global wetland inventory-current status and future priorities. Marine and Freshwater Research, v. 50, n. 8, p. 717$727,1999$.

FISHER, A.; FLOOD, N.; DANAHER, T. Comparing Landsat water index methods for automated water classification in eastern Australia. Remote Sensing of Environment, v. 175, p. 167-182, 2016.

FLEISCHMANN, A.; MATTIUZI, C.; KICH, E.; GONDIM, G.; RUHOFF, A.; PAIVA, R. et al. Avaliação da seca de 2016 do Rio Javaés (bacia do Rio Araguaia) com uso de dados de múltiplos satélites. Anais do XVII Simpósio Brasileiro de Sensoriamento Remoto, p. 5033-5040, 2017.

G1 TOCANTINS. Após seca, rio Formoso terá aparelho para monitorar retirada de água. 18/02/2017. Disponivel em: http://g1.globo.com/to/tocantins/noticia/2017/02/apos-seca-rioformoso-tera-aparelho-para-monitorar-retirada-de-agua.html. Acesso em: 05/05/2019.

GUO, M.; LI, J.; SHENG, C.; XU, J.; WU, L. A review of wetland remote sensing. Sensors, v. 17, n. 4, p. 777, 2017.

HAMILTON, S. K.; SIPPEL, S. J.; MELACK, J. M. Comparison of inundation patterns among major South American floodplains. Journal of Geophysical Research: Atmospheres, v. 107, n. D20, p. LBA 5-1-LBA 5-14, 2002.

HELSEL, D. R.; FRANS, L. M. Regional Kendall test for trend. Environmental science \& technology, v. 40, n. 13, p. 4066-4073, 2006.

HIRSCH, R. M.; SLACK, J. R. A nonparametric trend test for seasonal data with serial dependence. Water Resources Research, v. 20, n. 6, p. 727-732, 1984.

HU, S.; NIU, Z.; CHEN, Y.; LI, L.; ZHANG, H. Global wetlands: Potential distribution, wetland loss, and status. Science of the Total Environment, 586, 319-327, 2017.

IBGE, Instituto Brasileiro de Geografia e Estatística. Mapa Geológico do Tocantins. Coordenação de Recursos naturais e Estudos Ambientais, 1. ed. Rio de Janeiro, IBGE, 2007. Escala: 1.000.000.

IRION, G.; NUNES, G. M.; NUNES-DA-CUNHA, C.; DE ARRUDA, E. C.; SANTOSTAMBELINI, M.; DIAS, A. P., MORAIS, J. O.; JUNK, W. J. Araguaia river floodplain: size, age, and mineral composition of a large tropical savanna wetland. Wetlands, v. 36, n. 5, p. 945-956, 2016. 
JENSEN, J. R.; EPIPHANIO, J. C. N. Sensoriamento remoto do ambiente: uma perspectiva em recursos terrestres. São José dos Campos: 2da ed. Parêntese Editora, São José dos Campos, 2009. $598 \mathrm{p}$.

JORNAL NACIONAL. No Tocantins, a seca severa transforma rios em lagos. Por Jornal Nacional, 22h12, 30/09/2019. Disponível em: https://g1.globo.com/jornalnacional/noticia/2019/09/30/no-tocantins-a-seca-severa-transforma-rios-em-lagos.ghtml. acesso em: $05 / 12 / 2019$.

JUNK, W. J. Wetlands of tropical south America. In: Wetlands of the world: Inventory, ecology and management Volume I. Springer, Dordrecht, 1993. p. 679-739. JUNK, W. J. Current state of knowledge regarding South America wetlands and their future under global climate change. Aquatic Sciences, v. 75, n. 1, p. 113-131, 2013.

JUNK, W. J.; BAYLEY, P. B.; SPARKS, R. E. The flood pulse concept in river-floodplain systems. in: DOGE, D. P.(ed.). Proc. Int. Large River Symp (LARS) - Can. Spec. Publ. Fish. Aquat. Sci., 106, pp.110-127, 1989.

JUNK, W. J.; PIEDADE, M. T. F.; LOURIVAL, R.; WITTMANN, F.; KANDUS, P.; LACERDA, L. D.; AGOSTINHO, A. A. Brazilian wetlands: their definition, delineation, and classification for research, sustainable management, and protection. Aquatic Conservation: marine and freshwater ecosystems, v. 24, n. 1, p. 5-22, 2014.

KAHYA, E.; KALAYCI, S. Trend analysis of streamflow in Turkey. Journal of Hydrology, v. 289, n. 1-4, p. 128-144, 2004.

KANDUS, P.; MINOTTI, P. G.; MORANDEIRA, N. S.; GRIMSON, R.; GONZÁLEZ TRILLA, G.; GONZÁLEZ, E. B.; GAYOL, M. P. Remote sensing of wetlands in South America: status and challenges. International Journal of Remote Sensing, v. 39, n. 4, p. 993-1016, 2018.

LATRUBESSE, E; M.; STEVAUX, J. C. Características físico-bióticas e problemas ambientais associados à planície aluvial do rio Araguaia, Brasil central. Revista Geociências-UNG-Ser, v. 5, n. 1, p. 65-73, 2007.

MACKLIN, M. G.; LEWIN, J. River stresses in anthropogenic times: Large-scale global patterns and extended environmental timelines. Progress in Physical Geography: Earth and Environment, v. 43, n. 1, p. 3-23, 2019.

MALTBY, E. The Changing Wetland Paradigm. MALTBY, Edward; BARKER, Tom (Ed.). The Wetlands Handbook, 2 Volume Set. John Wiley \& Sons, 2009. pag. 1-42.

MAMEDE, L.; ROSS, J. L. S.; SANTOS, L. M. Geomorfologia. Projeto RADAMBRASIL, Levantamento de Recursos Naturais, Folha SC.22 Tocantins, Rio de Janeiro, MME/Secretaria Geral, 1981. v.22, p.197-248.

MARCUZZO, F. F. N.; CARDOSO, M. R. D.; FARIA, T. G. Chuvas no Cerrado da região CentroOeste do Brasil: análise histórica e tendência futura - Ateliê Geográfico, v. 6, n 2, p. 112-130, 2012.

MCFEETERS, S. K. Using the normalised difference water index (NDWI) within a geographic information system to detect swimming pools for mosquito abatement: a practical approach. Remote Sensing, v. 5, n. 7, p. 3544-3561, 2013. 
MCFEETERS, Stuart K. The use of the Normalized Difference Water Index (NDWI) in the delineation of open water features. International journal of remote sensing, v. 17, n. 7, p. 14251432, 1996.

MENDES, L. A. S. Dinâmica da paisagem na porção norte da Ilha do Bananal-TO e adjacências ao longo do Quaternário tardio. 2019. 130 f. Tese (Doutorado em Geologia e Geoquímica) Instituto de Geociências, UFPA, Belém, 2019.

MENESES, P., R; SANO, E., E. Sensor Radar de abertura sintética. IN: MENESES, P. R.; ALMEIDA, T. Introdução ao processamento de imagens de sensoriamento remoto. Brasília, 2011.

MITSCH, W. J.; GOSSELINK, J. G. The value of wetlands: importance of scale and landscape setting. Ecological economics, v. 35, n. 1, p. 25-33, 2000.

MORAIS, R. P.; AQUINO, S.; LATRUBESSE, E. M. Controles hidrogeomorfológicos nas unidades vegetacionais da planície aluvial do rio Araguaia, Brasil. Acta Scientiarum. Biological Sciences, v. 30, n. 4, p. 411-421, 2008.

MORAIS, R. P.; DE OLIVEIRA, L. G.; LATRUBESSE, E. M.; PINHEIRO, R. C. D. Morfometria de sistemas lacustres da planície aluvial do médio rio Araguaia; Acta Scientiarum. Biological Sciences, v. 27, n. 3, p. 203-213, 26 mar. 2008.

MPF - Ministério Público Federal. Índios da Ilha do Bananal (TO) buscam solução para deslocamentos devido à seca no rio Javaés. 11/07/2013 disponível em: http://www.mpf.mp.br/to/sala-de-imprensa/noticias-to/ministerio-publico-federal-promoveaudiencia-publica-sobre-a-falta-de-agua-potavel-em-aldeias-da-ilha-do-bananal. Acesso em: $08 / 12 / 2019$.

MPF - Ministério Público Federal. Índios da Ilha do Bananal (TO) buscam solução para deslocamentos devido à seca no rio Javaés. 11/07/2013 disponível em: http://www.mpf.mp.br/to/sala-de-imprensa/noticias-to/ministerio-publico-federal-promoveaudiencia-publica-sobre-a-falta-de-agua-potavel-em-aldeias-da-ilha-do-bananal. Acesso em: 08/12/2019.

NETO, V. L. S.; BARBOSA, L.; VIOLA, M. R.; MORAIS, M. A. V. Variabilidade espacial e temporal da precipitação no Estado do Tocantins, Brasil. Research, Society and Development, v. 10, n. 3, p. e44310313545-e44310313545, 2021.

ONOZ, B.; BAYAZIT, M. Block bootstrap for Mann-Kendall trend test of serially dependent data. Hydrological Processes, v. 26, n. 23, p. 3552-3560, 2012.

PEKEL, J. F.; COTTAM, A.; GORELICK, N.; BELWARD, A. S. High-resolution mapping of global surface water and its long-term changes. Nature, v. 540, n. 7633, p. 418-422, 2016.

R CORE TEAM: A language and environment for statistical computing. $R$ Foundation for Statistical Computing, Vienna, Austria, 2020. URL https://www.R-project.org/.

REBELO, L.-M.; FINLAYSON, C. M.; NAGABHATLA, N. Remote sensing and GIS for wetland inventory, mapping and change analysis. Journal of environmental management, v. 90, n. 7, p. 2144-2153, 2009. 
RIBEIRO, J. F.; WALTER, B. M. T. Fitofisionomias do bioma Cerrado. In: SANO, S. M.; ALMEIDA, S. P. de (Ed.). Cerrado: ambiente e flora. Planaltina: EMBRAPA-CPAC, 1998. p. 89166.

SANTOS, D.; MORAIS, F. A assimetria de bacias hidrográficas e influências litoestruturais na geomorfologia do rio Formoso, TO. Caminhos de Geografia, v. 18, n. 61, p. 180-199, 2017.

SANTOS, R. D.; CASTRO, D. L.; BEZERRA, F. H. R.; VIDOTTI, R. M.; FUCK, R. A.; DANTAS, E. L.; LIMA, T. P. C. Influência do Lineamento Transbrasiliano na formação do arcabouço estrutural da Bacia Parnaíba. In: 13th International Congress of the Brazilian Geophysical Society. Anais... Rio de Janeiro, Sociedade Brasileira de Geofísica, 2013.

SCHMIDT, G. L.; JENKERSON, C.; MASEK, J. G.; VERMOTE, E.; GAO, F. Landsat ecosystem disturbance adaptive processing system (LEDAPS) algorithm description. 2013.

SHAO, K.; ZHANG, J.; HE, K.; WANG, C.; LU, H. Impacts of the Wetland Environment on Demographic Development during the Neolithic in the Lower Yangtze Region-Based on Peat and Archaeological Dates. Frontiers in Earth Science, v. 9, p. 59, 2021.

SILVA A. J. P.; LOPES, R. C.; VASCONCELOS, A. M.; BAHIA, R. B. C. Bacias sedimentares paleozóicas e meso-cenozóicas interiores. In: BIZZI, L. A., SCHOBBENHAUS, C.; VIDOTTI, R. M.; GONÇALVES, J. H. (eds.) Geologia, Tectônica e Recursos Minerais do Brasil (texto, mapas e SIG). Brasília, Serviço Geológico do Brasil - CPRM/MME, 2003. p. 55-85.

SILVA, F.; P.; DA SILVA, T. M. Perfil de Relevo em Varredura: Procedimentos Automáticos Utilizando Sistemas de Informação Geográfica. Revista Brasileira de Cartografia, v. 70, n. 3, p. 846-866, 2018.

STEVAUX, J. C.; LATRUBESSE, E. M. Geomorfologia fluvial. São Paulo, Oficina de Textos, 2017.

STROPPER; J. L.; MARTINS, E. G.; FRASCA, A. A. S. Carta geológica folha SC.22-Z-A - Santa Teresinha. CPRM - Serviço Geológico do Brasil, Goiânia, 2014. Escala: 1:250.000.

TINER, R. W. Wetland Delineation: Overview. In: Finlayson C. et al. (eds). The Wetland Book. Springer, Dordrecht. 2016, p. 3- 18.

TURNER, R. K.; VAN DEN BERGH, J. C.; SÖDERQVIST, T.; BARENDREGT, A.; VAN DER STRAATEN, J.; MALTBY, E.; VAN IERLAND, E. C. Ecological-economic analysis of wetlands: scientific integration for management and policy. Ecological economics, v. 35, n. 1, p. 7-23, 2000.

UDDIN, K.; MATIN, M. A.; MEYER, F. J. Operational flood mapping using multi-temporal sentinel-1 SAR images: a case study from Bangladesh. Remote Sensing, v. 11, n. 13, p. 1581, 2019.

UMETSU, R. K.; GIRARD, P.; MATOS, D. M. D. S.; SILVA, C. J. D. Efeito da inundação lateral sobre a distribuição da vegetação ripária em um trecho do rio Cuiabá, MT. Revista Árvore, v. 35, p. 1077-1087, 2011.

VALENTE, C. R.; LATRUBESSE, E. M. Fluvial archive of peculiar avulsive fluvial patterns in the largest Quaternary intracratonic basin of tropical South America: the Bananal Basin, CentralBrazil. Palaeogeography, Palaeoclimatology, Palaeoecology, v. 356, p. 62-74, 2012. 
VALENTE, C. R.; LATRUBESSE, E. M.; FERREIRA, L. G. Relationships among vegetation, geomorphology and hydrology in the Bananal Island tropical wetlands, Araguaia River basin, Central Brazil. Journal of South American Earth Sciences, v. 46, p. 150-160, 2013.

$\mathrm{XU}, \mathrm{H}$. Modification of normalised difference water index (NDWI) to enhance open water features in remotely sensed imagery. International journal of remote sensing, v. 27, n. 14, p. 3025-3033, 2006.

XU, Y. hyfo: Hydrology and Climate Forecasting R Package for Data Analysis and Visualization. 2020.Disponivel em: http://yuanchao-xu.github.io/hyfo/

YAN, X.; BAO, Z.; ZHANG, J.; WANG, G.; HE, R.; LIU, C. Quantifying contributions of climate change and local human activities to runoff decline in the upper reaches of the Luanhe River basin. Journal of Hydro-environment Research, v. 28, p. 67-74, 2020.

ZANI, H.; ROSSETTI, D. F. Multitemporal Landsat data applied for deciphering a megafan in northern Amazonia. International Journal of Remote Sensing (Print), v. 33, p. 6060-6075, 2012.

ZAPROWSKI, B. J.; EVENSON, E. B.; EPSTEIN, J. B. Stream piracy in the Black Hills: a geomorphology lab exercise. Journal of Geoscience Education, v. 50, n. 4, p. 380-388, 2002.

ZHUANG, Y.; KIDDER, T. R. Archaeology of the Anthropocene in the Yellow River region, China, 8000-2000 cal. BP. The Holocene, v. 24, n. 11, p. 1602-1623, 2014.

Trabalho enviado em $21 / 07 / 2021$

Trabalho aceito em 30/12/2021 